\title{
HACIA UN CATALOGO \\ DE LA OBRA \\ MUSICAL DEL \\ COMPOSITOR \\ COLOMBIANO \\ CARLOS \\ POSADA \\ AMADOR
}

Luis Carlos Rodríguez Álvarez1

luiscarlos.lcrodrig@gmail.com

(DOI: 10.17230/ricercare.2015.3.5)

1 Luis Carlos Rodríguez Álvarez, médico cirujano e historiador pertenece al grupo de investigación INTERDIS de la Universidad Nacional de Colombia,

sede Medellín, a su vez es profesor en la Universidad Nacional de Colombia y

Universidad de Antioquia. Tiene publicaciones nacionales e internacionales. 
Resumen

Se presenta un catálogo actualizado de las obras musicales del compositor y pedagogo Carlos Posada Amador (* Medellín, 25 de abril de 1908 - † México, D. F., 22 de diciembre de 1993), quien, en su labor como creador, encontró en las más variadas tradiciones, escuelas, corrientes y estilos de la música occidental y de la cultura universal las mejores fuentes para su escritura musical.

Palabras clave: historia de la música, Antioquia, Colombia, México, Carlos Posada Amador.

\section{Abstract}

This article presents an updated catalogue of musical works by Colombian composer and teacher Carlos Posada Amador (* Medellin, April $25^{\text {th }} 1908$ - $\dagger$ Mexico City, December 22th 1993). The most varied traditions, schools, currents and styles of Western music and world culture acted as the best sources of Posada Amador's compositions.

Keywords: History of Music - Antioquia - Colombia Mexico - Carlos Posada Amador.

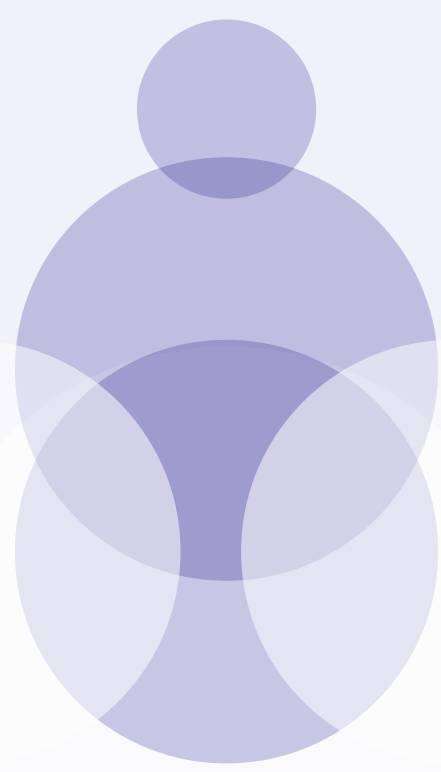



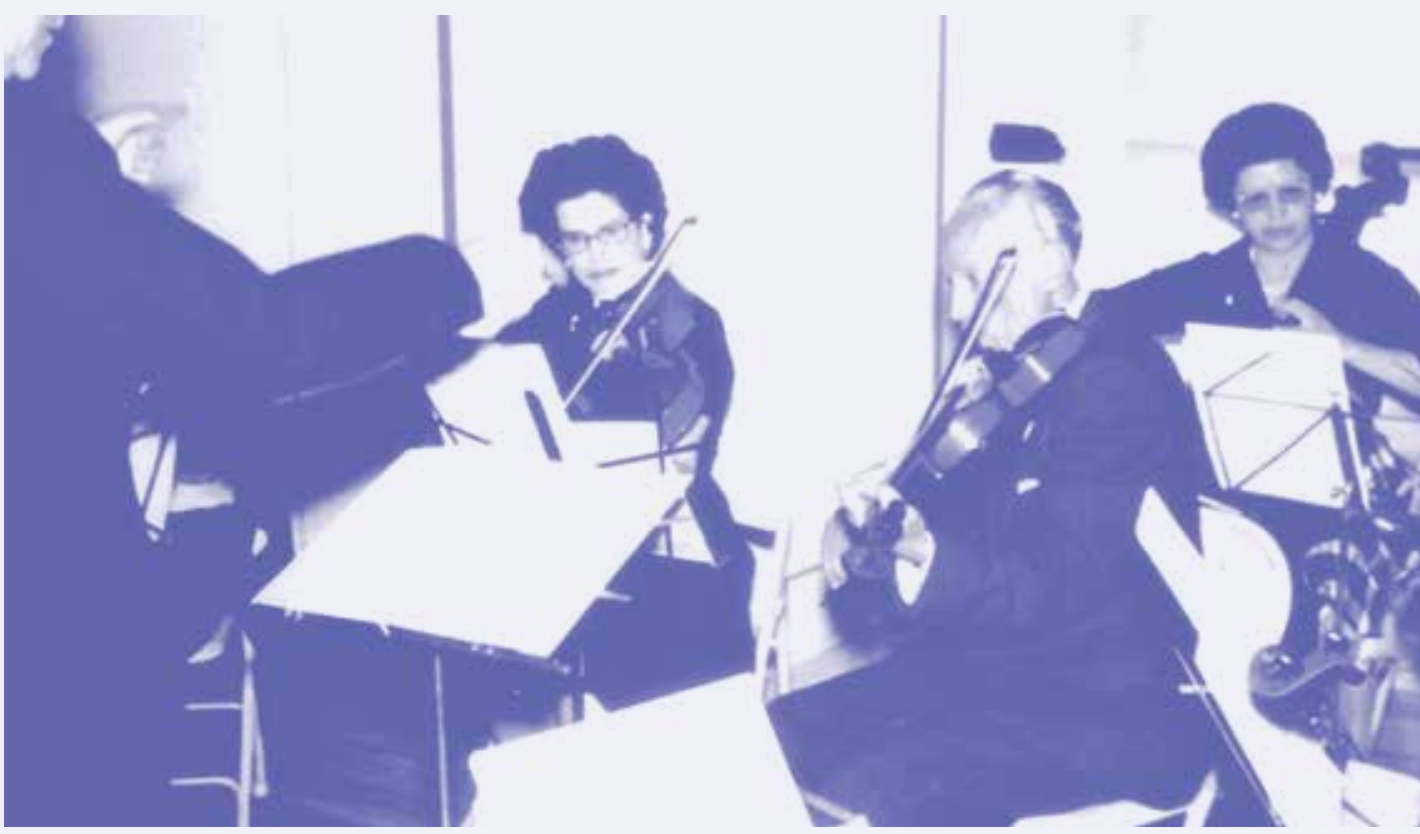

\section{INTRODUCCIÓN}

El compositor antioqueño Carlos Posada Amador nació en Medellín el 25 de abril de 1908 y murió en Ciudad de México el 22 de diciembre de 1993. Luego de iniciar estudios musicales en su ciudad natal, junto a Pedro Begué y Germán Posada Berrío, en 1927 se residenció en París, donde se graduó en 1934 como Profesor de Contrapunto, habiendo tomado cursos de armonía, contrapunto, dirección de orquesta y composición, en la Schola Cantorum y en la Ècole Normale de Musique, con los maestros Vincent d'Indy, Nadia Boulanger y Paul Dukas.

A su regreso, en 1934, en Bogotá, fue discípulo de Guillermo Uribe Holguín, entonces director del Conservatorio Nacional. Entre 1935 y 1937, Posada Amador ocupó el cargo de director del Palacio de Bellas Artes de Medellín, destacándose como uno de los más entusiastas animadores del ambiente cultural de la ciudad por esos años.

En 1942, buscando mejores horizontes para su actividad musical, viajó a México, estableciéndose en la capital azteca y desde entonces allí residió, dedicado a la composición y a la pedagogía -en la Escuela de Música de la Universidad Nacional Autónoma de
México y en el Conservatorio Nacional-. A su fallecimiento, era considerado como el "decano de los creadores musicales eruditos de Colombia”.

Su obra original, escrita dentro de formas clásicas y románticas tradicionales, con algunas referencias a la música antigua, acordes con su formación europea, apenas empieza a ser divulgada y conocida en nuestro país, y cubre casi todos los géneros. Sin pretender análisis musicológicos, este trabajo presenta un catálogo actualizado de esa obra musical.

Sin pretender análisis musicológicos, este trabajo presenta un catálogo actualizado de la obra musical del compositor y pedagogo colombiano Carlos Posada Amador (* Medellín, 25 de abril de 1908 - † México, D. F., 22 de diciembre de 1993).

Con los datos que obtuvimos del mismo compositor en una discreta pero reveladora correspondencia, entre 1988 y 1992-, y después de su fallecimiento, con su hija Cecilia, y la revisión directa de sus archivos, hemos elaborado un catálogo de su obra que puede ser el más completo hasta hoy, pues amplía y corrige los hasta ahora conocidos, aparecidos en revistas, enciclopedias y libros de divulgación y referencia, tanto nacionales 
como internacionales (Colcultura, 1992, pp. 91-93; Espinosa Grau, 1964, pp. 120-123; Mayer-Sierra, 1.947, p. 789; Pardo Tovar, 1966, pp. 292-293; Sadie, 1980, p. 570; Zapata Cuéncar, 1973, p. 92). Además, sin detallar el catálogo, se menciona al compositor en Anglés y Pena (1954, p. 1.973); Anglés y Subirá (1965, p. 1.823); Dufourcq (1969, p. 331); Matas (1966, p. 809); Riemann (1975), 196 Scholes (1964, p. 988), Valls Gorina (1967, tomo IV, p. 30) y Zapata Cuéncar (1962, p. 56).

Como se dijo antes, se trata solo de un trabajo descriptivo, sin análisis musicológico alguno; una simple y sencilla enumeración, a partir de los hallazgos de archivo -circunstanciales, escritos, partituras, cartas y algunas breves audiciones-, que busca revelar los materiales disponibles, y pone en conocimiento de futuros investigadores la música de este desconocido compositor colombiano, exiliado en forma voluntaria en México los últimos 50 años de su vida. Lo que sí se puede decir es que él encontró, en las más variadas tradiciones, escuelas, corrientes y estilos de la música occidental y de la cultura universal, las mejores fuentes para su escritura musical.

La crítica apenas sí conoce la labor creativa de Posada Amador. Muy breves y esporádicos comentarios aparecieron en publicaciones de ocasión, para el estreno o la rara edición de alguna partitura, tal como se anota en su momento.

No muy extensa, pero sí muy depurada y seria, es esta producción musical. Sus trabajos completos, entre originales y arreglos, apenas pasan de la cincuentena, y abarcan casi todos los géneros. Su labor compositiva formal definitiva comenzó luego de su viaje de estudios a Europa y a su muerte aún no concluía.

Solo hasta agosto de 1994, la Dirección de Extensión Cultural Departamental de la Gobernación de Antioquia presentó al público un disco de acetato, el volumen 9 de la serie La música en Antioquia, que incluye una muy pequeña e incompleta muestra de la obra musical -camerística, coral y vocal- de Posada Amador
(Gobernación de Antioquia, 1994).2 Concebido como un homenaje en vida, por lamentables circunstancias apenas alcanzó a ser póstumo.

Apenas se inicia el conocimiento y la publicación de las obras de Carlos Posada Amador. Por mencionar solo algunos comentarios, tanto el profesor Otto de Greiff (1995) como el maestro Mario Gómez-Vignes (en carta a Luis Carlos Rodríguez; Cali, 30 de enero de 1995) reseñaron en su momento, con laudatorias y amables palabras, la presentación pública del disco de homenaje.

Luego de la grabación de este disco, el mismo año el Centro de Documentación y Edición Musical de Antioquia. Notas y partituras (1995), bajo la dirección del compositor y pedagogo Andrés Posada Saldarriaga, editó en forma impecable, como el primer número de la colección Compositores colombianos, su pieza Seis Variaciones sobre "Estrellita" de M. M. Ponce, para violín y viola.

Estas publicaciones han permitido también la realización de conciertos conmemorativos en varios centros musicales y universidades, en los que se han incluido obras vocales y de cámara. Así, en la comentada vigésima audición del Ciclo compositores colombianos y norteamericanos del siglo XX (Barreiro Ortiz, 1995), del Centro Colombo Americano de Bogotá, a principios de junio de 1995, en la que se escucharon obras vocales, camerísticas y corales, y en un concierto especial en la Facultad de Artes de la Universidad de Antioquia de Medellín, con un programa similar.3

Por otro lado, y desde 1995, en el programa institucional Mil años de la música y en varios conciertos del Festival Internacional Música de Cámara Colombiana

2 En el disco se incluyeron la Melodía rústica, la Cantiga navideña, las canciones Nocturno, En la playa de Sanlúcar y A fin de que los vientos, versiones para cuarteto vocal mixto de Romanza, Canción de amor naciente y Canción de amor desdeñado (tres de las Canciones medievales) y Román Castillo (uno de los Romances mexicanos) y la Fuga en si bemol para órgano.

3 Se escucharon el Minueto para arpa, la Melodía rústica, las canciones A fin de que los vientos y Nocturno, el Trio para flautas y clarinete, las Cinco canciones medievales y tres Romances mexicanos para coro mixto. 
de Medellín, organizado por el Grupo de Investigación Audiovisual INTERDÍS de la Universidad Nacional de Colombia, sede Medellín, se han interpretado en vivo algunas canciones y piezas camerales, en diversos formatos, y se estrenaron sus piezas pianísticas. ${ }^{4}$

Y desde 2003, en la serie radial Compositores colombianos, de la emisora 95.9 de la Fundación Cámara de Comercio de Medellín para Antioquia, se han realizado varios espacios dedicados a Posada y su obra.

Pero más interesante es el que puede ser considerado como una forma de gratitud en su segunda patria: durante la Sexta Semana Cultural de Colombia en México, el 26 de julio de 1997, se presentó en estreno una delicada selección de la obra vocal y cameral del creador antioqueño, en el programa Encuentro en México de un compositor colombiano y un compositor italiano: Carlos Posada Amador y Umberto Zanolli ${ }^{5}$.

Sobre el conjunto de esta producción es muy difícil hacer un comentario extenso, debido a que, por deseo expreso del autor, apático por publicar, su obra permaneció inédita y desconocida en nuestro país, en la práctica, hasta su muerte.

Al respecto, podemos citar inicialmente dos textos memorables. El primero es de Otto de Greiff, quien sintetizó en 1944, poco después del viaje definitivo del compositor a México, todo lo conocido sobre el músico antioqueño, comentando la reciente publicación de las Cinco canciones medievales:

Para que sus paisanos crean muy poco en Carlos Posada Amador les basta el saberlo descendiente de un famoso millonario antioqueño del siglo pasado. Pero tiene también muy probada ascendencia musical, por ambas ramas. Nació el 28 de abril de 1908, en Mede-

4 Entre las obras interpretadas en esta serie de programas se cuentan las canciones $A$ fin de que los vientos, En la playa de Sanlúcar, Nocturno y Dos canciones griegas, las Dos piezas para piano, el Cuarteto breve "El hijo pródigo”, Canon, coral y fuga para cuarteto de cuerdas y piano y algunas de las Variaciones sobre "Estrellita” de M. M. Ponce.

5 Se escucharon en dicho concierto la Melodía rústica, las Variaciones sobre "Estrellita" de M. M. Ponce y las canciones A fin de que los vientos, En la playa de Sanlúcar y dos Canciones sobre poesías de sor Juana 106 Inés de la Cruz. lín. Su educación musical es esencialmente francesa, y puede enorgullecerse de haber estudiado con tres eminentes figuras: Vincent d'Indy, Paul Dukas y Nadia Boulanger. Al regresar a su terruño debió sorprenderle demasiado el contraste entre su refinada cultura musical y el pobre ambiente que lo circundaba; esto explica el enclaustramiento de Posada dentro de sí mismo, y su extraordinaria reserva para dar a conocer los frutos de su talento. En 1938, cuando el Centenario, la Orquesta Sinfónica Nacional, dirigida por el famoso musicólogo compositor ruso-estadounidense Nicolás Slonimsky, interpretó "La Coronación del Zipa en Guatavita", la orgullosa timidez de Posada le impidió venir a la capital a presenciar su triunfo. Dedicado durante todo este tiempo a menesteres prosaicos, Posada compone en sus múltiples ratos de ocio. La obra mencionada es la única que rinde pleitesía al espejismo de la música nacional; las demás podrían haber sido firmadas por un europeo. Posada Amador conoce vastamente el idioma y las formas musicales antiguas y es un apasionado de los viejos modos griegos y cristianos y de las escalas orientales. Así se explica que haya dado a Curt Lange, Cinco Canciones Medievales para coro mixto a cappella, sobre textos utilizados por los viejos trovadores franceses, textos traducidos al español y adaptados, por el propio Posada. Nuestro compositor armoniza viejas monodias medievales: una Romanza anónima del siglo XIII, una Canción de Mayo, del trovador Moniot de Arras, una Canción de Amor Desdeñado, también anónima del siglo XIII, como la Canción de Amor Naciente; y la Canción Cortés, del trovador del siglo XII Jaufré Rudel (De Greiff Häusler, 1944).

El segundo es de Andrés Pardo Tovar, poco más de 20 años después:

En las primeras obras de Posada Amador, es visible la influencia del impresionismo debussysta: Así, en la Cantiga Navideña y en el poema sinfónico $\boldsymbol{L a}$ Coronación del Zipa en Guatavita (...) Sin apartarse de esta técnica, bien que interpretándola a base de una sensibilidad nacionalista, escribió las Cinco Canciones Medioevales y el Coral Fúnebre (...) En 
México renueva su estilo y perfecciona sus técnicas contrapuntales, y comienza a escribir obras que transparentan ya un verdadero encuentro con su propia personalidad creadora (Pardo Tovar, 1966).

Sin embargo, este comentario, escrito a mediados de los años sesenta, no está contextualizado y contemporizado, si tenemos en cuenta las nuevas y posteriores versiones de las obras comentadas, no alcanzadas a conocer por Pardo Tovar.

En la edición de 1980 de The New Grove Dictionary of music and musicians, el compositor es incluido en el artículo dedicado a Colombia, en el que se lo vincula, en el sentido estético, con una especie de "neo-romanticismo combinado a un subjetivo nacionalismo", entre un grupo de autores de nuevas generaciones que "desarrollan un estilo ecléctico", al decir de la misma obra (Sadie, 1980).

El legado estético completo de Carlos Posada Amador no puede situarse o encasillarse en las estructuras de un determinado estilo musical, corriente estética o escuela artística definidos en la historia. Sus preferencias

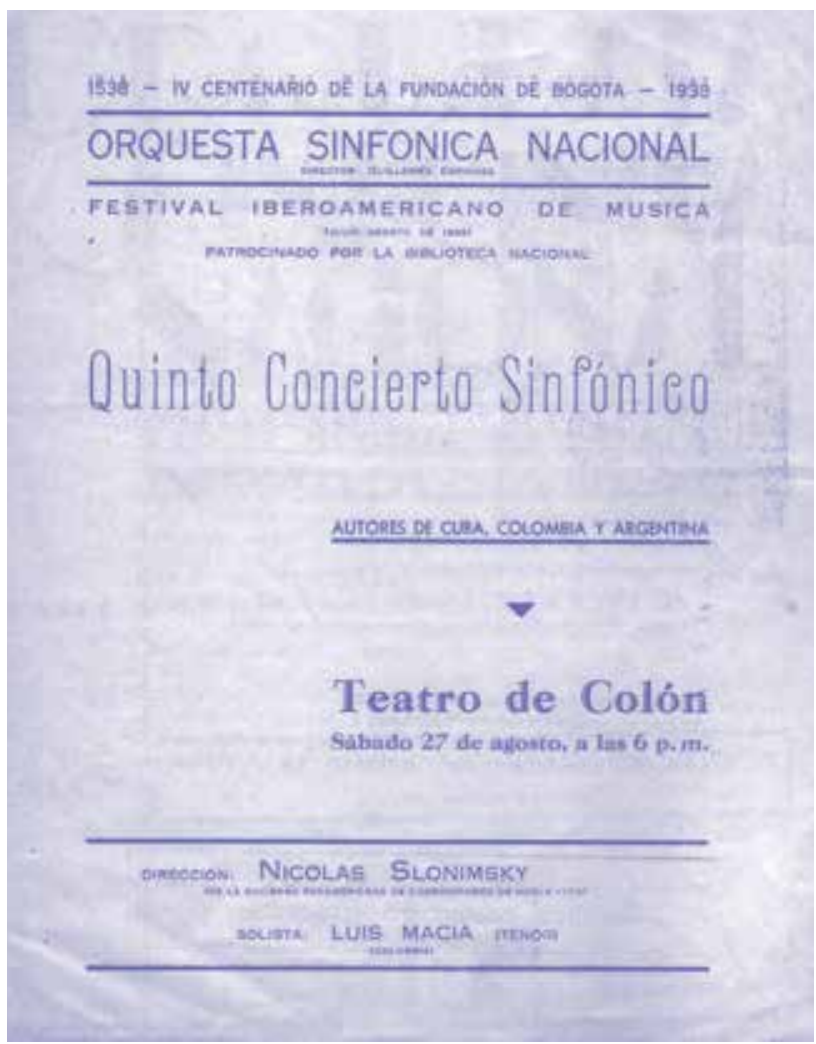

al componer lo ubican, sobre todo, en las formas clásicas tradicionales, desde el medioevo y el renacimiento hasta el romanticismo alemán y el impresionismo francés. Su música es tonal, sencilla, fácil, amable y muy agradable de escuchar... En definitiva, su trabajo no se aclimata a las vanguardias.

Su propia hija, al recoger los comentarios del público común y las opiniones no especializadas después de las audiciones realizadas en México, nos escribió:

Algunas personas dicen que su música es tierna, dulce, nostálgica y un tanto triste. Es una música muy refinada, melancólica, emotiva, que no pretende impresionar por sonidos ultramodernos ni ritmos extravagantes. Las piezas para arpa y flauta son sobrias, mesuradas, finas y delicadas. Las canciones y piezas para voces, lo mismo. Diría yo que es música intimista. Sin embargo, necesitaría conocer las partituras para orquesta para poder formarme una opinión más amplia de la obra en general (Cecilia Posada Jiménez en carta a Luis Carlos Rodríguez; México, 10 de abril de 1998).

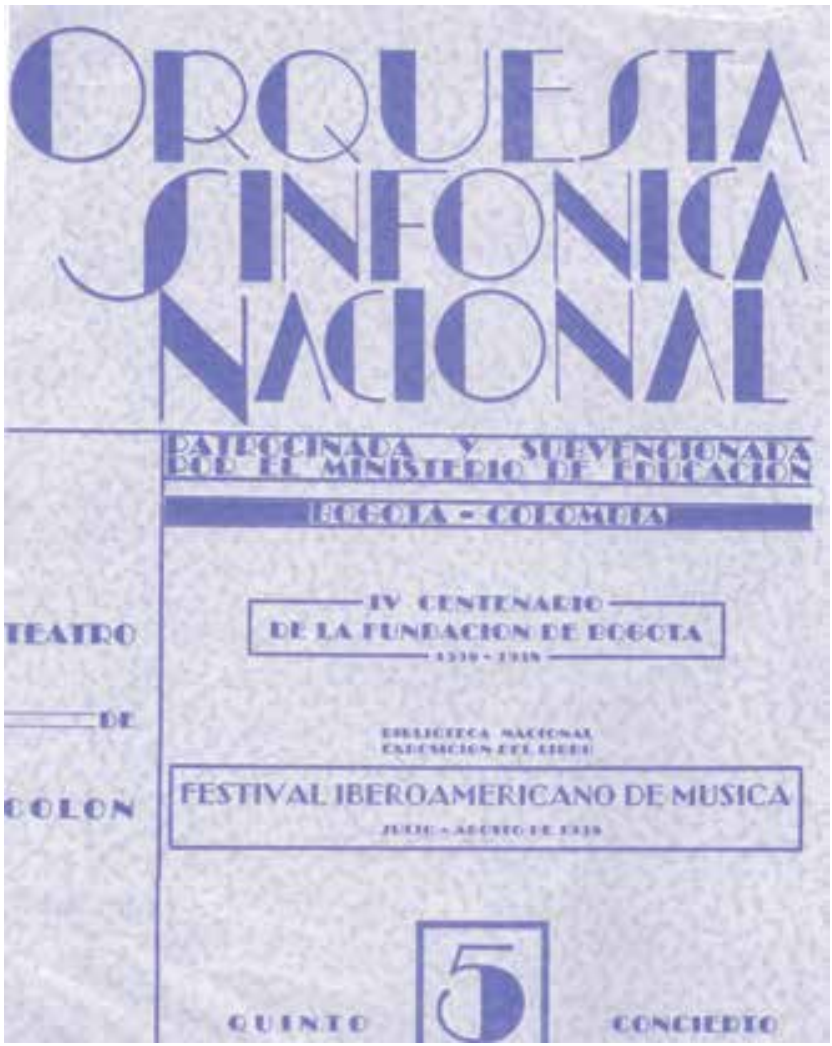


Y una autorizada opinión, que intenta defender el íntimo y libertario acto creador de Posada Amador, es la del maestro Gustavo Yepes Londoño, compositor, director, pianista y pedagogo, exdecano de la Facultad de Artes de la Universidad de Antioquia y prestante docente en el Departamento de Música de la Universidad EAFIT de Medellín:

En él hay un lenguaje tonal, que a veces tiene un delicadísimo pantonalismo... correspondiendo histórica y estilísticamente a su formación tanto en la escuela impresionista de Debussy como en la menos revolucionaria de la Schola Cantorum de d'Indy. Su actitud creadora es común a todo lo francés: más clásico y menos romántico... Más cartesiano, cientificista y racional, que los apasionados germanos. No hay en la música de Posada Amador nada que signifique un simple afán de "descrestar". Su interés radica en la expresión de sí mismo, de su íntimo afecto hacia lo clásico, y de mostrar su profundo conocimiento de los lenguajes y estilos contenidos en la historia musical de Occidente... No le interesan las vanguardias ni los modernos... ¿Pero es que acaso un compositor o un artista creador tiene que someterse a las vanguardias de su tiempo?... Esa tendencia tan común a los artistas desde finales del siglo XIX y principios del XX... Por todo ello, Posada tiene histórica y estéticamente un sitio de honor en la mejor música nacional colombiana (Gustavo Adolfo Yepes Londoño: comentarios personales; Medellín, noviembre de 1998).

Proponiendo una personal tesis de trabajo, hemos de considerar a Carlos Posada Amador como uno de los representantes del llamado eclecticismo musical de nuestro país, si se entiende dicha denominación en el mejor y más positivo significado y se la despoja de su connotación peyorativa.

Ecléctico, pues al bucear en toda su obra original se nota que Posada selecciona de manera consciente determinados elementos de diversos estilos, sin que los

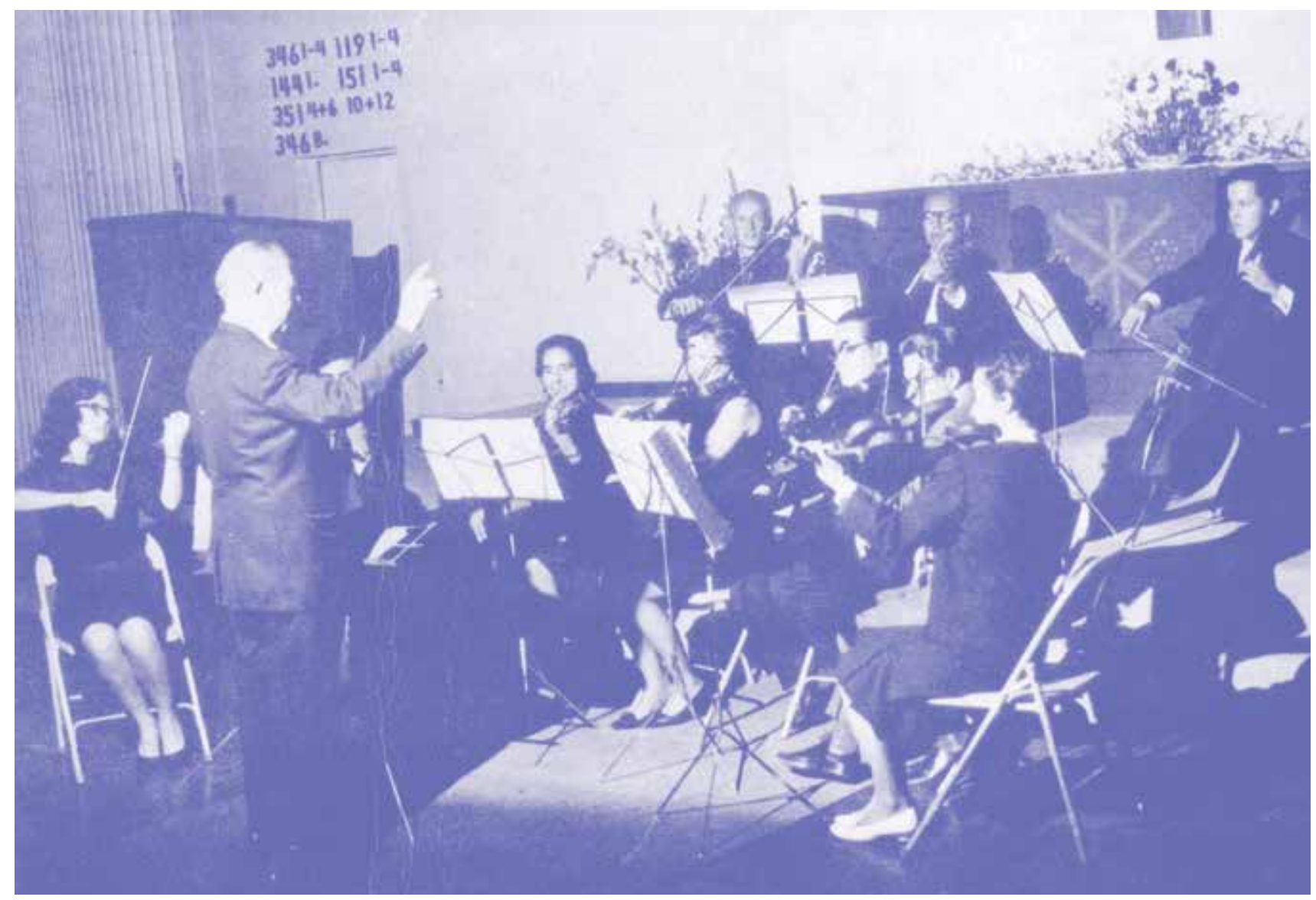


mismos, en virtud de un potente estilo personal, se fundan completamente en un todo. En este sentido, eclecticismo no es, pues, lo contrario de originalidad. De hecho, grandes maestros, como Bach, Mozart y Beethoven, quizás no fueron tan originales en cierto sentido como Chopin o el joven Schumann; también aquellos escogieron de sus predecesores y contemporáneos para asimilar por completo a su personalidad lo escogido ciertamente. Mendelssohn, en cambio, debe ser tenido en parte como ecléctico, pues los estilos peculiares de Bach y de Händel han permanecido como cuerpos extraños, sin fundirse, en su lenguaje musical.

Para situarlo de alguna manera en la escena colombiana, la obra de Posada Amador pudiera vincularse, quizás, a la del creador bogotano Fabio González Zuleta (1920-2011), reconocido en forma abierta e íntima como ecléctico, tanto por él mismo como por los musicólogos estudiosos de su obra. Sin embargo, a diferencia de González, y como ya lo anotamos, Posada nunca incursionó en los terrenos de la música de vanguardia, fue menos ambicioso y muchísimo más desconocido.

Como aquel, Posada Amador escribe cada partitura con antera libertad, tal vez de manera independiente. Cada obra ha sido un mundo aparte, una visión distinta, con una inspiración diferente, sin relación con las demás; no ha sido continuación ni ha estado emparentada con otras.

En su catálogo encontramos partituras en todos los estilos, siempre en la tradición musical europea. Conocedor profundo de cada uno de ellos, mantiene un gran interés y cuidado por la forma. Esto le permite una posibilidad variada para sus más íntimas expresiones. Sin seguir siempre la misma línea, cada obra tiene su propia estructura, su propia técnica. De acuerdo con sus necesidades específicas y sus intenciones creativas, emplea la técnica y el estilo en el que se siente más a gusto. Para cada obra se ha imbuido de la estética pertinente y ha obedecido a una determinada situación o parámetro musical o extramusical, como si viviera una actitud artística libre o libertaria ante determinados momentos y circunstancias emotivas y mentales. "No es un compositor inspirado, sino un compositor erudito" (Gustavo Adolfo Yepes Londoño: comentarios personales; Medellín, noviembre de 1998).

El musicógrafo Carlos Barreiro Ortiz, uno de los organizadores del concierto con obras de Posada Amador que se realizó en Bogotá en junio de 1995, escribe una amplia e interesantísima aproximación crítica que aporta mucho en el estudio del autor antioqueño. Por ello, se reproduce íntegra:

Esta música se escucha en la actualidad como una especie de reflexión acerca de formas y expresiones musicales ya superadas, a través de las cuales se percibe la inclinación del autor hacia estilos polifónicos de la antigüedad musical, del barroco español, además de una clara influencia de las armonías disciplinadas de la música francesa del post-romanticismo... Ante la certeza que se deriva de la audición del conjunto de piezas camerísticas y vocales, aparecidas en el disco conmemorativo, se perfila la imagen de un autor dueño de un estilo anacrónico a su tiempo (inclusive si se habla de neoclasicismo) cuyos parámetros no sufrieron mayores variaciones al contacto de la escena musical mexicana. En la década de los años cuarenta, cuando Posada abandona su país, la música de México atravesaba por un período de búsquedas modernistas, alejadas del nacionalismo de origen folclórico y popular de años anteriores, y se orientaba hacia el indigenismo como estímulo, por una exuberancia orquestal exótica y disonante, como se aprecia en algunas obras de Carlos Chávez. En forma casi simultánea se sucede la desaparición de Silvestre Revueltas, autor de una música compleja, a veces agresiva o llena de humor -en una nota suelta hablaba del "... silencio marchito de la tarde, como un Vargas Vila desamparado...", al referirse al sonido del saxofón-, y la llegada al país, desde España, de Rodolfo Halftter, cuya enseñanza del sistema dodecafónico proporcionaría nuevos aires al deseo de componer música que se revelara mexicana y americanista al mismo tiempo... Posada Amador sale 
incontaminado de todas estas posibles influencias. Su única incursión en el tema indigenista - La coronación del Zipa en Guatavita- se había escuchado en Bogotá en 1938, y su estilo había sido calificado de "wagneriano". Las composiciones camerísticas fechadas después de su llegada a México ni siquiera podrían calificarse de modernistas, teniendo en cuenta el gusto del autor por el contrapunto preclásico. Por el contrario, algunas de las canciones para voz y piano demuestran una línea de expresión más fluida, aunque comprometida con el marco de la chanson française de finales del siglo XIX.... La obra de Posada Amador ejemplifica la libertad del artista para escoger los elementos que le proporcionan los medios destinados a la búsqueda de su expresión personal. Al fin y al cabo, la herencia técnica y formal del arte europeo, hace parte del conocimiento que tenemos del mundo que se quiere transformar a través del acto creativo de los artistas.... Aventurando una hipótesis, el espíritu general de la obra de Posada Amador -a la cual se tiene acceso-, representaría la influencia tardía de casi tres siglos del barroquismo religioso implantado por la colonización española, lo cual impidió el acceso racional y oportuno al rigor de las normas formales del período clásico. La obra de Posada Amador sería, entonces, como el eslabón encontrado entre el conjunto de la música que se ha escrito en Colombia en las últimas cinco décadas y el repertorio intrascendente que nos dejara el período republicano (Barreiro Ortiz, 1995, p. 11).

Para poner fin a la discusión, el mismo compositor nos afirmó en forma categórica que no se consideraba perteneciente a una tendencia o escuela musical determinada. A la pregunta de si había detectado alguna influencia de otros autores en su obra, nos respondió:

No. Porque no es posible explicar eso. La influencia de un músico sobre otro es muy sutil... De mí sé decirle que mis preferidos son Beethoven, Haydn, Mozart, Bach, Orlando di Lassus, Josquín des Prés y Palestrina. Además, Wagner, Debussy, Ravel y un poco Verdi. Como ve usted, no es posible explicar este punto (Carlos Posada Amador en carta a Luis Carlos Rodríguez; México, 18 de octubre de 1988).
Tal vez solo el tiempo, juez supremo, que pone todo en perspectiva, dirá en realidad la última palabra sobre este legado estético. Se hacen necesarias las completas edición, grabación y audición por parte del público y la lógica investigación profunda y analítica de musicólogos y estudiosos formados en estas disciplinas, definitivamente mucho más autorizados. Este modesto trabajo es solo una invitación a ese análisis y estudio.

Para terminar esta introducción, un proverbial colofón personal... Con la sabiduría que da una larga vida, llena de innumerables experiencias en el campo artístico, y dueño de una original forma de entender su labor creativa, nuestro biografiado comenta:

Lo único que le puedo decir de mi actividad artística, es que uno percibe más o menos la belleza musical y trata de comunicarla al oyente con sonidos dispuestos en cierta forma, que es lo que constituye la composición musical. Uno nunca queda satisfecho del resultado y nunca sabe si el oyente captó la visión... Pero así son las cosas y hay que contentarse con hacerlo lo mejor que uno puede (Carlos Posada Amador en carta a Luis Carlos Rodríguez; México, 19 de septiembre de 1988).

\section{CATÁLOGO POR GÉNEROS}

En este catálogo hemos clasificado, por su naturaleza, los siguientes géneros y obras. Las fechas entre paréntesis corresponden a las de composición y, cuando hay dos, a las primeras versiones y a las revisiones finales; se agregan tonalidades, dedicatorias y otros datos marginales:

\section{Música vocal}

Dos canciones griegas (1934-1960), sobre poemas de Safo ("Epitafio"), en re frigio, y Anacreonte ("Vejez"), en si frigio, traducidos al francés por Mario Meunier, am-

6 Mario Meunier (1880-1960) fue un helenista francés, traductor a su lengua, entre otros, de Platón, Safo, Sófocles, Nono de Panópolis, Eurípides, Hiérocles de Alejandría, Proclo, Homero, Plutarco y Pitágoras. Fue, además, autor de obras originales: La leyenda dorada de los dioses 
bas para canto (contralto y barítono) y arpa (o piano). A fin de que los vientos... (1935-1977), con versos del profesor Otto de Greiff; En la playa de Sanlúcar (19351985), en sol menor, sobre texto propio; Canción de la vida profunda (1939-1978), en si bemol (dedicada a Ignacio Isaza Martínez) y Nocturno (1978), en sol bemol mayor, sobre los poemas homónimos de Porfirio Barba Jacob, y cinco Canciones (1992), con poesías de Sor Juana Inés de la Cruz, para canto (soprano) y piano.

\section{Música coral}

Cántiga navideña (1934-1977), en fa sostenido mayor, para soprano, contralto y tenor, con acompañamiento de flauta, arpa, triángulo y trombones (dedicada a Alicia Amador de Posada) con texto latino, y Camino de Belén (romance tradicional mexicano) (1968), en sol mayor, para coro mixto con acompañamiento de cuerdas y flauta dulce.

Himno Panamericano (o Latinoamericano) (1978), en fa mayor, con letra de Rodolfo Brito Moreno, e Himno Universitario (1984), letra del compositor, en si bemol mayor, ambos para coro y orquesta, aunque del segundo existe versión para coro y piano.

Madrigal (1932) (en honor a Nadia Boulanger); Elegía (1935), sobre texto propio, en mi bemol mayor, para coro masculino, Cinco canciones medioevales (19381939); Diez romances tradicionales mexicanos (1954) (dedicado al eminente folclorista y maestro Vicente T. Mendoza); Florilegio Lírico Coral I (Canciones escocesas y Romances tradicionales mexicanos) (1967); Canon (1968), a cuatro voces mixtas, con letra de una copla popular mexicana, sobre el tema de la "Fuga del gato" de Doménico Scarlatti; Florilegio lírico coral II (canciones rusas y corales) (1977), y Juguete vocal, sobre la melodía de El trino del diablo de Giuseppe Tartini, obras todas para coro mixto a cappella, originales, armonizadas, traducidas y en arreglos.

\section{Música orquestal}

y de los héroes (en dos volúmenes) y Leyendas épicas de Grecia y Roma, Historias sagradas del Antiguo y del Nuevo Testamento, una especie de Antología de Libros Santos y La leyenda de Sócrates.

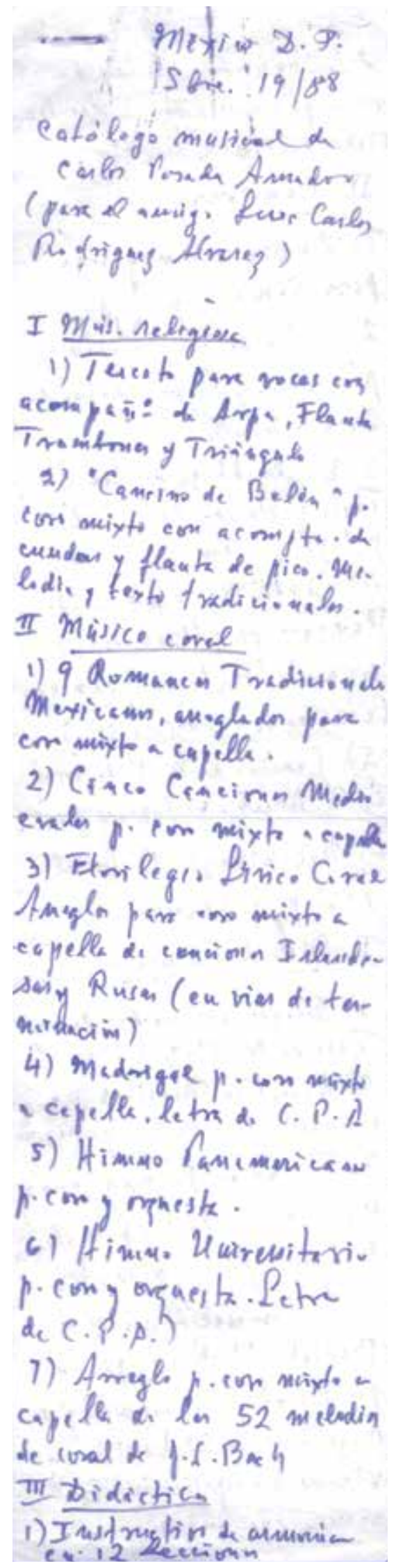


Obertura de recepción (1934), en re mayor; La coronación del Zipa (primera versión), poema sinfónico-coreografía musical en tres partes (1938), en mi bemol mayor; Concierto barroco para clavecín, cuerdas y otros instrumentos (flauta, clarinete, corno, trompeta y triángulo) (1981), en si bemol mayor (dedicado a Margarita Posada Amador), y La coronación del Zipa (segunda versión), ballet en un acto (1991).

Rubaiatas (o suite lírica persa) (1934-1992), para canto (barítono) y orquesta, sobre textos de Omar Khayyam, traducidos al francés por Mario Meunier, y Crespos Caimán, ópera sobre tradiciones antioqueñas, con texto propio, en la cual trabajaba todavía al momento de su muerte.

\section{Música de cámara}

Minueto (1933-1975), en fa mayor, para arpa cromática; Dos piezas ["Campanas" (o El campanario de Martinville) y "Surtidor"] (1934) para piano; Fuga, en re menor, a cinco voces (1958) y Fuga, en si bemol mayor, a cuatro voces (1960), para órgano; Preludio, Fuga y Tocatta (1989), para guitarra (dedicado a su sobrino Carlos Ignacio Vieira Posada), y La coronación del Zipa (1991), versión para piano de la obra homónima.

Melodía rústica (1933-1973), en sol menor, para flauta y arpa, y Trío (1976), en si bemol, para dos flautas y clarinete (dedicado a Germán Posada Berrío y a Guillermo Uribe Holguín).

Coral fúnebre (1937), en fa mayor, para septeto de bronces y timbales (dedicado a la memoria de Alberto Castilla); Sagitario (1958), en si bemol mayor, para quinteto de alientos, y Fuga (1968), en si bemol mayor, para cuarteto de alientos.

Cuarteto № 1, op. 4 (1924), en fa mayor, y Cuarteto breve ("El hijo pródigo") (1992), en re mayor, para cuarteto de cuerdas; Canon, coral y fuga (1953), en sol bemol mayor, para cuarteto de cuerdas y piano, versión definitiva de la obra homónima para órgano, dedicada a Juan Diego Tercero Farías); Dúos № 1 (1953), № 2 ("Tema y variaciones sobre un nombre") (1972) y № 3 (1978), en do mayor, para violín y viola, y Seis variaciones sobre "Estrellita" de M. M. Ponce (1963), para igual formación instrumental (dedicada a la memoria del compositor Manuel María Ponce).

Son suyos también, muchos arreglos para diversas formaciones. Así, una versión orquestal del Preludio al primer acto de [El sueño de] Fervaal de Vincent d'Indy (1925); el acompañamiento al segundo movimiento sobre el bajo continuo del Concierto Il Gardellino de Antonio Vivaldi; un arreglo para cuerdas del Divertimento K. Anh. 229 № 1 de Wolfgang Amadeus Mozart (1958-1969); una versión para dos flautas del Concierto Pastoral de Johann Melchior Molter (1967); una orquestación para vientos y timbales del anónimo Himno holandés (1968), y una parte adicional para viola del Concierto en fa mayor de Johann Adolph Hasse (1968).

\section{CATÁLOGO CRONOLÓGICO - ANEXO ANALÍTICO}

Viene a continuación el que sería nuestro aporte personal. A cada obra original le hemos asignado un número clasificatorio particular, basados en el número encontrado en la primera obra conocida, op. 4, asignado por el mismo compositor en 1924. Muy joven, él estaba concibiendo tal vez un futuro catálogo personal, que luego desechó. Solo continuamos la numeración cronológica. En la mayoría de las obras, con mayor o menor extensión, hemos intentado un análisis.

Primera época: los inicios

A continuación se enumeran algunas piezas, hasta ahora desconocidas, que hemos encontrado en la casa del compositor en Ciudad de México. Se trata muy probablemente de unos bocetos personales, apenas borradores o intentos de obra, trabajos que deben considerarse esfuerzos precoces de estudiante de composición, pues el mismo Posada nunca los llegó a incluir en su propio catálogo y solo fueron conocidos en época reciente al rescatarlos de su archivo particular. 
Un cuadernillo grapado contiene las primeras tres piezas: un apunte para piano y dos canciones, así:

1. [Apunte]. Se lee manuscrito y con lápiz, en el margen superior, "Mi primera pieza acabada"]. Una página. A pesar de lo que menciona, el manuscrito que el autor del artículo tiene a la vista se interrumpe en el compás número 13.

2. [Dos canciones]: Desilusiones, para canto y piano. Poesía de Pietro [¿?]. Se lee "1a․ y ¿1922? (con lápiz, en el extremo derecho y en el centro, en su orden). Tres páginas. Tempo: moderato maestoso. Hacia lo infinito. Poesía de Alicia A[mador] de P[osada] [su madre]. En la primera página se lee “2ª y op. 1 (con lápiz, en el extremo izquierdo y en el centro, en su orden) y en la tercera página, en el borde izquierdo “¿1922-3? Mi segunda pieza, vocal, acabada”, y en el borde superior “Para pieza sinfónica”, todo con lápiz). Tempos: grandioso et lento y andante, en su orden.

3. Paisage [sic] Escandinavo. Dedicado a la primavera Julio. Se lee manuscrito y con tinta "op. 1. Piano", andante assai, en el extremo superior izquierdo; el título y el subtítulo al centro, y "por Dn. José (ilegible) y Posada", en la esquina superior derecha. Es una obra completa, de 32 compases, separada, con escritura formal, en tinta.

4. Cuarteto № 1, op. № 4, para dos violines, viola y violoncello. En la portada, con lápiz, se informa: Vichy y París, Francia, 1924. Escrito en la tonalidad de fa mayor, en cuatro movimientos: I. Moderato - Un poco più lento - Tempo I - Allegro con brio. II. Andante Moderato - Tempo I - Moderato - Tempo I. III. Allegretto - Allegro Moderato. IV. Algo vivo - Allegro molto. En un cuadernillo de 25 páginas. Es la única obra de esta época que el compositor considera en su catálogo personal. 


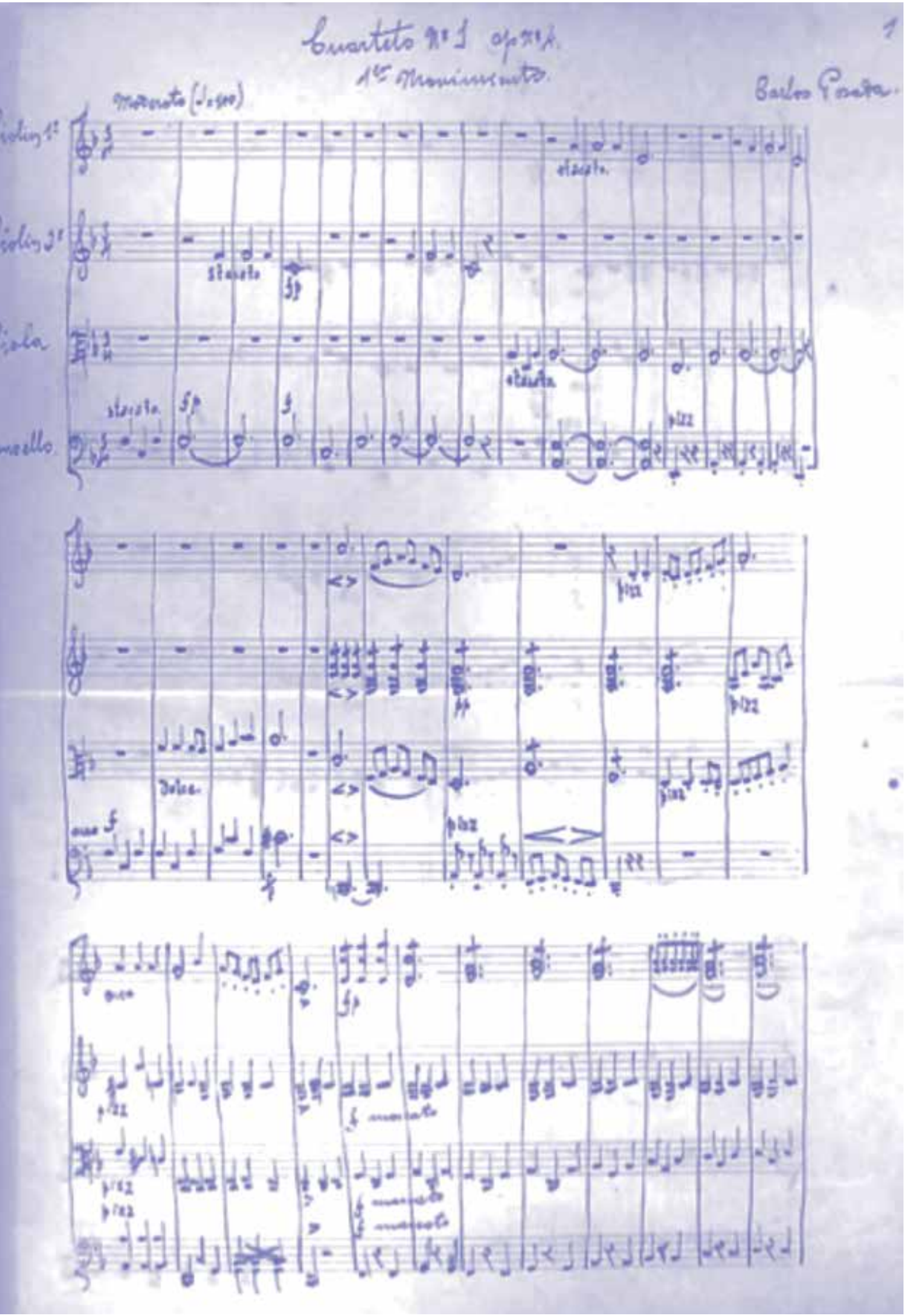


5. [La rienda suelta largamente al lloro] [Último verso del soneto Agora con la aurora de fray Luis de León], compuesto entre el 24 y el 26 de septiembre de 1926 . Todo escrito con lápiz.

Ahora, varias piezas que muy probablemente estuvieron destinados a la orquesta del maestro Pedro Begué.

6. 1 a. Sinfonía (con tinta). Se lee en el borde superior de la primera página "Enero - Abril 1924, Medellín, Antes del 1er. Viaje" (con lápiz). Tempos: Allegro - Andante. Se conservan seis páginas, en un cuadernillo grapado.

7. [Obra orquestal] A (La) mayor. 1‥ Tempo. Andante Allegretto - Ier. Tiempo (con tinta), "Enero - Abril 1924, Medellín, Antes del 1er. Viaje" y "op. 2" Tema de una misa contemporánea de M. C. P. (cuando me prestó Dn. Pedro B[egué] el tratado sobre harmonía (con lápiz). Ocho primeras páginas.

8. $1^{\circ}$ (Poemitas sinfónicos árabes). Para orquesta de maderas [2, 2, 2, 2] y cuerdas [5]. Tempos: Un poco andante - Allegro (con lápiz se lee "Desarrollarlo más para el cuarteto", al comienzo de esta parte. Nueve páginas.

9. Madrigal, para coro mixto a cuatro voces. Creado en París, en 1932, está dedicado a su profesora Nadia Boulanger. Es la única obra escrita durante sus años de estudio en Francia.

10. Melodía rústica, para flauta y arpa. Esta obra, en la tonalidad de sol menor, está fechada en su primera versión con el nombre de Cantinela, el 23 de octubre de 1933, y está dedicada a su tío Germán Posada Berrío, flautista, y a su hermana Margarita Posada, arpista, con la indicación del tempo en moderato. Según la fecha, sería la primera obra escrita en Colombia, tras su regreso de Francia. Tiene dos revisiones: una del 31 de enero de 1962, en la que toma el nombre francés definitivo, y el tempo dice In ritmo di barcarolla comodo, y la definitiva, del 5 de octubre de 1973. Se trata de una sencilla y pequeña pieza, plena de intimidad y frescura, tonal y tradicional, que supone una fácil y agradable audición. Por los instrumentos escogidos, se adivina una intención familiar y una reminiscencia pastoril y francesa. Por sus elementos modales, desde el punto de vista estilístico se le puede enmarcar en las disciplinas musicales posteriores al romanticismo galo, tal vez en el ambiente de la escuela impresionista de Debussy, del cual hay quizás algunos recuerdos. Fue grabada en el disco y ha sido incluida en casi todos los conciertos recientes.

11. Minueto, para arpa cromática, en fa mayor. Escrito en 1933, la versión definitiva data de 1975 y está dedicado a su hermana, doña Margarita Posada de Vieira, arpista destacada en su juventud. Es una pieza elegante, grácil y sencilla, pequeña joya característica, escrita en el ambiente de la antigua danza folclórica francesa, de la cual toma su nombre, y en la cual se conservan la estructura ternaria y el trío, que la han hecho tan popular.

12. Rubaía (№ 72), para canto (barítono) y orquesta, sobre texto de Omar Khayyam, traducido al francés por Mario Meunier, en fa sostenido moderno menor. Esta obra, fechada el 11 de enero de 1934, es la primera terminada y la sexta del ciclo denominado por el compositor Rubaiatas de Omar Khayyam o Suite lírica persa, para la cual concibió siete piezas que ponen en música las famosísimas cuartetas del escritor iraní del siglo XI. Infortunadamente, solo concluyó dos, esta y la № 114, designada en este catálogo con el númeral 20.

Según el diseño original, la obra ordenaba los poemas 114, 84, 86, 101, 170, 72 y 80, según número en el libro de traducciones de Meunier. Les asignó las siguientes tonalidades, en su orden: fa sostenido hipofrigio mayor, fa hipolidio mayor, la moderno mayor, sol sostenido dorio menor, do sostenido frigio menor, fa sostenido moderno menor y do sostenido minolidio mayor.

Se trata de una visión muy personal, definitivamente íntima, de las Rubaiatas, fabulosa creación literaria sobre la naturaleza del universo, el transcurso del tiempo y la relación entre el hombre y Dios, colección por la cual es famoso en Occidente el matemático, físico, astrónomo, médico, filósofo y poeta persa. 
13. Obertura de recepción, para orquesta sinfónica, en re mayor. Según la copia de la partitura que tenemos a la vista, fue terminada en Medellín, el 5 de marzo de 1934, y estrenada por la orquesta del Conservatorio de Bellas Artes de Medellín, bajo la dirección del autor, con ocasión del primer concierto del Segundo Congreso Nacional de Música, el 5 de julio de 1937. En palabras del propio Posada Amador, "simplemente era un saludo musical a los congresistas. Es una obrita muy sencilla" ( Carlos Posada Amador: Carta a Luis Carlos Rodríguez. México, 20 de abril de 1989.

14. Dos piezas para piano ("Cloches"y "Jet d'eau"). Se trata de dos pequeñas obras, piezas cortas pero muy expresivas, las únicas escritas directamente para el instrumento (la otra obra catalogada es una versión reducida -o transcripción pianística- de su ballet La coronación del Zipa). Consideradas siempre como obras menores, apuntes o bosquejos, y no como trabajos definitivos, se conservan en sendos manuscritos con tinta, con apuntes en francés, en un papel de score (para escribir para orquesta). Desde el mismo nombre, con títulos muy poéticos que se traducirían algo así como Campanas y Surtidor, en su orden; en ambas piezas se alienta, indiscutiblemente, una concepción descriptiva, casi imitativa, del ambiente bucólico de la campiña francesa, y del espíritu y el lenguaje impresionista fruto de la formación del compositor. Muy sugestivo de su rigurosa intención es la nota marginal del autor, escrita en francés, en la segunda obrilla: “El ejecutante está obligado a tocar esta pieza de una manera muy limpia, con una rítmica nítida impecable y dando una rica sonoridad a las características y a los acentos".

La primera obra se denomina Campanas, aunque el propio autor la llama El campanario o simplemente Campanario en algunas de sus relaciones y catálogos personales. Con un tempo asignado como lento, la pieza fue terminada en Bogotá el 5 de mayo de 1934, ocupa una página y media y está escrita en apenas 44 compases. La segunda, llamada Surtidor, en tempo moderato, fue concluida 12 días después y está consignada en 51 compases.
Este trabajo dio origen a un artículo publicado por el profesor Jairo Enrique Restrepo, en el cual hace un interesante análisis y la edición crítica de ambas piezas (Restrepo Restrepo, 2010).

En tiempo reciente, después de la publicación del mencionado artículo, encontramos, entre los manuscritos del compositor, una versión terminada (corregida) de la primera pieza. Titulada Le Clocher de Martinville, en la misma partitura (ya en cuatro páginas, tempo andante y en otra armadura) remite en forma directa a la imagen que sugiere la descripción: el texto Les clochers de Martinville, un extracto de Por el camino de Swann, primer volumen de la magnífica novela À la recherche du temps perdu, (en francés) o En busca del tiempo perdido, del escritor francés Marcel Proust (1913). 

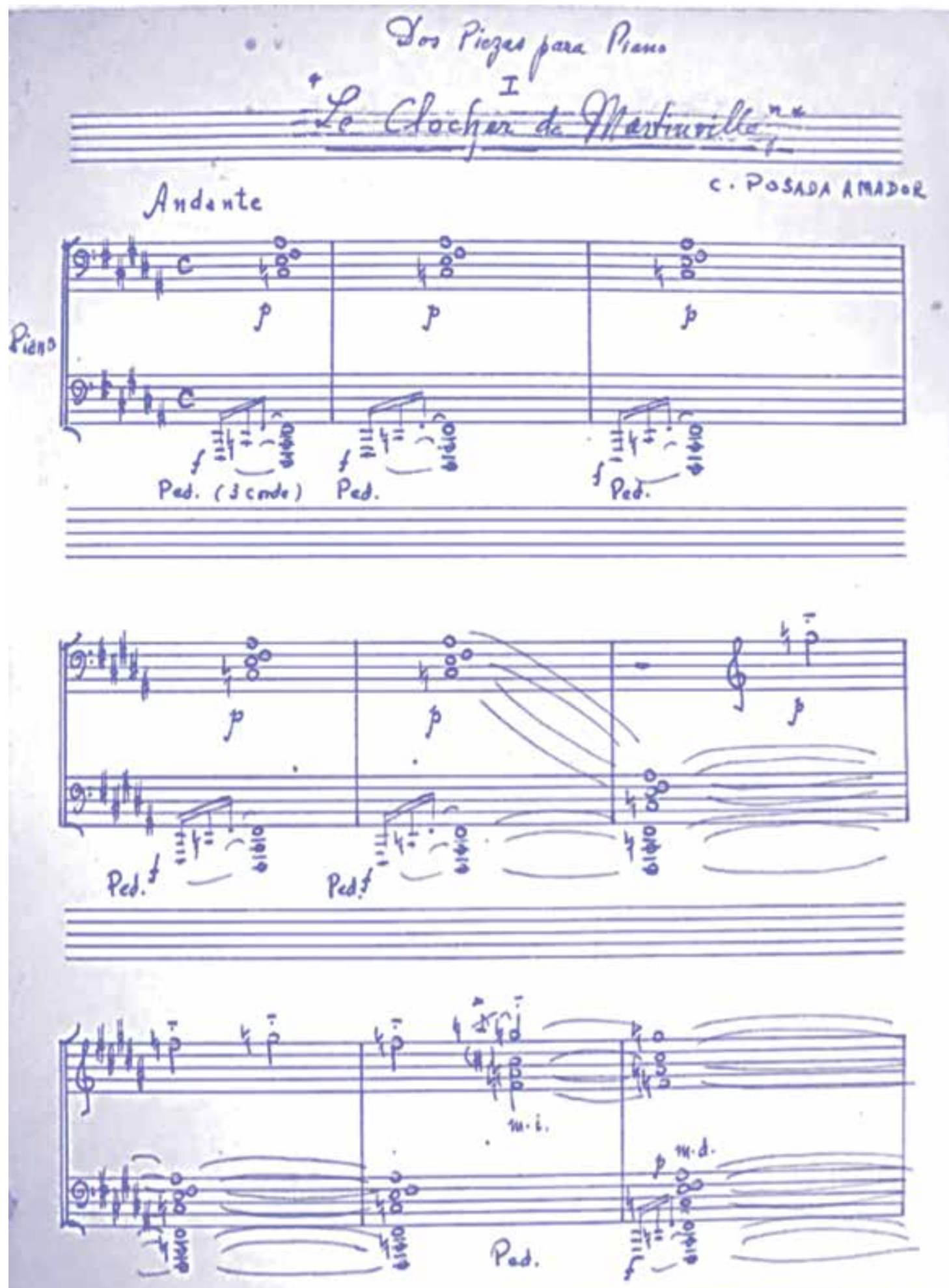

10 is is is is 
15. Dos canciones griegas, para canto y arpa (o piano), sobre poemas de Safo (Epitafio) y Anacreonte (Vejez), traducidos también al francés por Mario Meunier. Por el autógrafo sabemos que fueron terminadas en Bogotá el 3 de septiembre de 1934, e interpretadas en el primer concierto del Segundo Congreso Nacional de Música (Medellín, 5 de julio de 1937), por Ana Villamizar y Luis Macía, cantantes, acompañados por Margarita Posada, arpista. La revisión fue hecha en México el 17 de abril de 1960, con cambio de registro de canto de tenor a barítono, y de tempo, que pasó de moderato a ligero, en la segunda pieza. En ellas se identifica plenamente el conocimiento y la innata disposición del compositor hacia el espíritu clásico griego, su literatura y su música, y su predilección por un par de textos curiosos, sugerentes de la preocupación o interés por el final de la vida. Fueron publicadas en la Revista Universidad de Antioquia en 1989.

La primera está escrita en re frigio, para voz de contralto, y se denomina Epitafio. Está basada en el famoso Epitafio de Timas de Safo, la poetisa griega célebre por la armonía de sus versos y la ternura de sus confesiones amistosas hacia el círculo de muchachas que instruía en Mitilene, Lesbos, hacia el año 600 a. de C. y a quien en la antigüedad se considera la décima Musa.

La segunda se llama Vejez y está escrita en si frigio, para voz de barítono. Se conserva una copia de la primera página de la versión original en la que se lee, en francés: "El intérprete hará esta canción con mucho espíritu e irónica melancolía”. Original de Anacreonte, el célebre vate jónico de la corte ateniense, este texto nos muestra con toda exactitud al cantor de los placeres que trae el vino: aunque es, en esencia, el poeta del placer, cuando se plantea el problema de la vejez y de la muerte no lo hace en actitud grave ni desesperada, sino con cierta bonachona ironía e, incluso, dándonos una caricatura de sí mismo; hay melancolía, pero no trágica reflexión en sus versos, deliciosamente recreados por la música de Posada.
16. En la playa de Sanlúcar, para canto (contralto) y piano, sobre texto propio. Escrita en sol menor, está fechada Bogotá el 8 de septiembre de 1934, y fue revisada por el autor en México, el 10 de septiembre de 1985. Fue, quizás, la primera obra suya presentada en público; esta página vocal fue escuchada en el Gran Festival Hispanoamericano de Música, realizado en el Teatro Colón de Bogotá, el 5 de noviembre de 1934, por la animación de Guillermo Espinosa Grau. También ha sido incluida en el disco y en varios recitales de homenaje.

A pesar del muy personal tratamiento, esta verdadera joya en miniatura es una obra escrita con toda la esencia del alma y el sabor de la mejor música española, al estilo de las Canciones amatorias de Granados. En ella se viste con música un corto poema original, en el que se escucha, con impresionante efecto vocal, el íntimo, desgarrador y pasional lamento de la amante olvidada.

17. Cantiga navideña, para voces de soprano, contralto y tenor, con acompañamiento de flauta, arpa, triángulo y tres trombones. Escrita en fa sostenido mayor, sobre palabras latinas de la segunda antífona del tercer nocturno, el día de Navidad, según se expresa en el manuscrito. La obra fue dedicada a Alicia Amador de Posada, madre del compositor, para su sexagésimo cumpleaños, el 27 de octubre de 1934. La primera versión, para trío vocal y arpa, bajo el nombre de Cantiga sagrada para Navidad, data del 2 de agosto de ese año, con revisiones sucesivas en 1936 y 1943. La versión final es del 9 de octubre de 1977 y en ella se amplía la instrumentación. También fue grabada en el disco-homenaje comentado.

Tras el estreno de su segunda versión, en el primer concierto del Segundo Congreso Nacional de Música (Medellín, 5 de julio de 1937), por Ana y Sofía Villamizar y Luis Macía, cantantes, acompañados por Margarita Posada, arpista, fue publicada en el Suplemento Musical anexo al Boletín Latinoamericano de Música, que se editó con ocasión del Festival Iberoamericano de Música de Bogotá, en 1938. 
La Cantiga sagrada para Navidad es una fina, sencillísima y delicada creación, un vitral sonoro sugestivo y evocador en el que se puede adivinar la influencia de Nadia Boulanger. A pesar de que la riqueza armónica, en el papel jugado por los trombones en forma de interludio, nos recuerda un poco la tradición barroca anterior al estilo de Bach y Händel, esta pieza refleja un sentir muy personal en torno a la más noble fiesta del mundo cristiano.

18. Elegía, para coro masculino a cuatro voces, en mi bemol menor, sobre un texto propio. Compuesta en Medellín, el 25 de febrero de 1935, esta obra posee todas las características propias del madrigal: una canción profana polifónica, sin acompañamiento. Una vez más, sobre un tejido armónico tradicional sumamente exquisito y expresivo, en ella Posada Amador reflexiona con melancolía y tristeza acerca de la muerte y su gentil tranquilidad.

19. A fin de que los vientos... con versos del profesor Otto de Greiff, para canto (soprano) y piano. Escrita en Medellín, el 3 mayo de 1935, esta pieza vocal fue revisada en Ciudad de México, el 24 de noviembre de 1977. Presenta un precioso epígrafe en alemán (cuya traducción podría ser algo así como "Ven a mí -o entra en mí-/y silenciosamente cierra tras de ti las puertas", que don Otto de Greiff parafrasea y amplía, según su costumbre, en el tercer párrafo de su poema), original del poeta Friedrich Rückert, tomado del lied de Franz Schubert Du bist die Ruh' (Tú eres la calma), D. 777, o, en la antigua nomenclatura, op. 59 № 3. También fue incluida en el disco y en varios recitales de homenaje.

A fin de que los vientos... es una obra vocal sobria, muy elegante, impecable en la forma y amplia en su potencia expresiva; comprometida con la chanson française de finales del siglo XIX, a la manera de Fauré y Duparc, su discurso melódico está subrayado por una nueva experimentación de la sonoridad, muy sometida al verso. Conservo con sumo orgullo una grabación en la cual el poeta me lee esta canción; no sobra comentar lo intrínsecamente musical de las frases.
20. Rubaía № 114, para canto (barítono) y orquesta, sobre texto de Omar Khayyam, traducido al francés por Mario Meunier, en fa sostenido hipofrigio mayor. Esta obra, fechada el 14 de diciembre de 1936, es la segunda terminada y la primera del ciclo denominado por el compositor Rubaiatas de Omar Khayyam o Suite lírica persa, ya comentadas con amplitud en el numeral 12 de este catálogo. Concisas sentencias sobre la brevedad de la vida y el destino humano, deslumbrantes cuadros de naturaleza, ardientes efusiones de amor, espléndida poesía del siglo XI a la que viste de gala la transparente y delicada orquestación de Posada Amador.

21. Coral fúnebre, para septeto de bronces (dos trompetas, dos trompas, dos trombones y tuba) y timbales. Escrito en fa mayor, fue concluido en junio de 1937. Se estrenó como obra inaugural del primer concierto del Segundo Congreso Nacional de Música (Medellín, 5 de julio de 1937), en homenaje al maestro Alberto Castilla, fallecido apenas unos días antes, y quien fue el brillante y lamentado ausente del evento, pues gracias a su iniciativa se pudieron realizar este Congreso y su precedente, en Ibagué, en 1935. Actuaron como intérpretes miembros de la Orquesta del Conservatorio de Bellas Artes de Medellín, bajo la dirección del autor. En la partitura manuscrita, que tenemos a la vista, se pueden observar, debajo del título, las sucesivas dedicatorias tachadas: "En memoria del maestro Alberto Castilla (1883-1937)" y "p[ara] conmemorar la muerte de un hombre ilustre". Según datos de doña Cecilia Posada, la hija del compositor, hay tres hojas adicionales, con una reinstrumentación de 1964. 


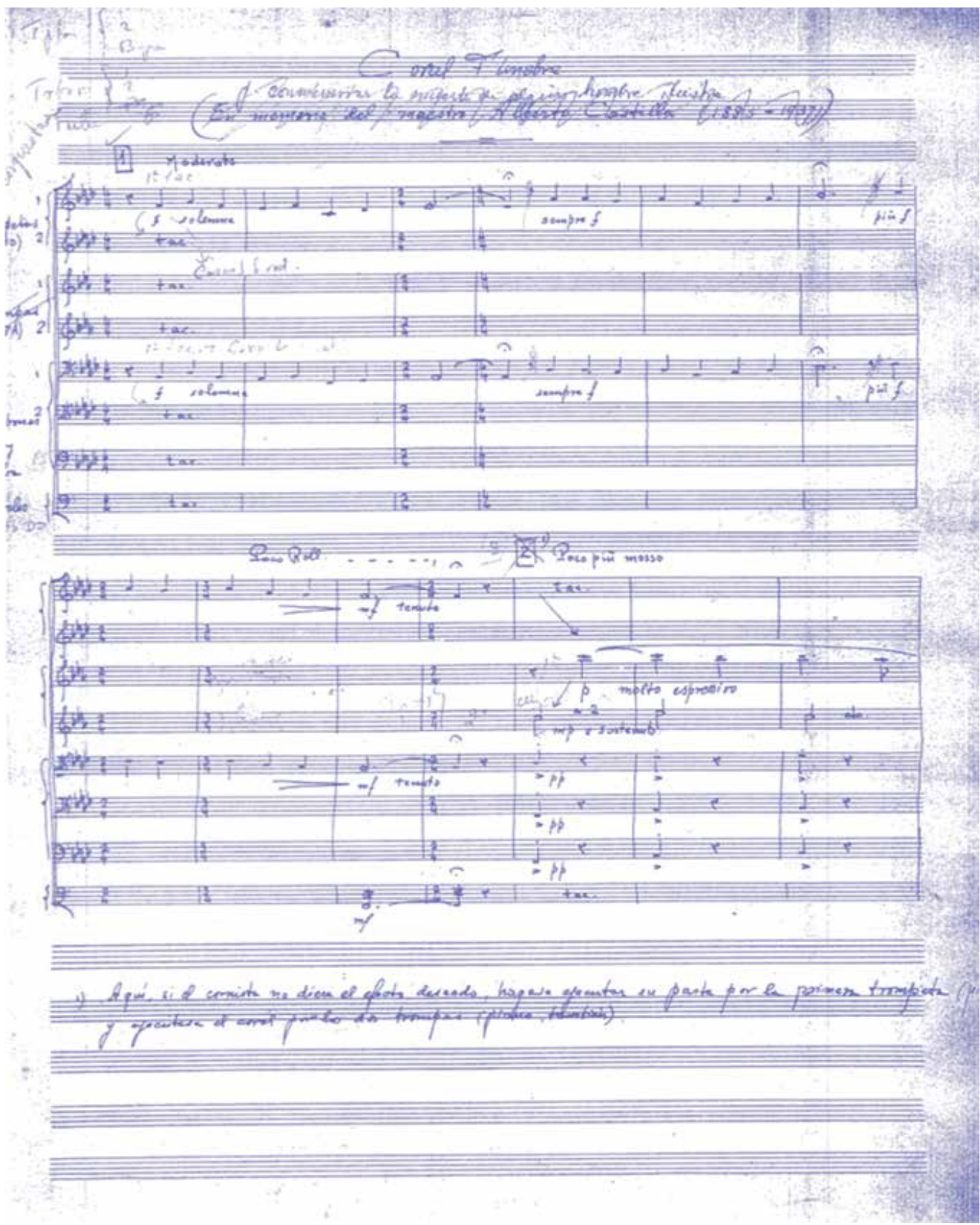


22. La coronación del Zipa (primera versión), coreografía musical en tres partes, en mi bemol mayor, para orquesta sinfónica. Terminada en mayo de 1938, la obra fue estrenada por la Orquesta Sinfónica Nacional bajo la dirección de Nicolás Slonimsky, para abrir el Quinto Concierto del Festival Iberoamericano de Música de Bogotá, el 27 de agosto de ese año, en el Teatro de Colón de Bogotá. Slonimsky, compositor, musicólogo, historiador y director norteamericano de origen ruso, asistió como delegado especial de la Sociedad Panamericana de Compositores de New York al evento.

El compositor escribió el siguiente texto para el programa:

Los Zipas o señores del pueblo chibcha eran coronados en Guatavita, según el ritual de la raza. El futuro rey era conducido ante la laguna sagrada, desnudo, ungido con oro en polvo y sumergido en las aguas de donde emergía rey nuevo. La presente coreografía musical pretende dar breve descripción sinfónica de dicha festividad, sirviéndose de algunos elementos del folklore casi desaparecido de esos lejanos tiempos. Escalas, ritmos, sonoridades y armonías, melismos autóctonos, forman la trabazón de la obra. En un cuadro y dividida en tres partes que se siguen sin solución de continuidad, la $C o$ ronación del Zipa se desarrolla así:

\section{I (AMANECER)}

Sobre las aguas dormidas de la laguna, la aurora se refleja y enciende las policromías diurnas. Precedido del trinar de las aves, el sol asoma triunfal, llenando la inmensidad celeste; día. (Escalas pentatónica y diatónica, elementos utilizados del folklore).

\section{II (RITOS)}

Precedido de trompetas, aparece el futuro Zipa. Clamores. Acompañados de músicas rituales los sacerdotes desnudan y ungen al elegido. Ungido por el ritmo ancestral, el Zipa se lanza al seno de las aguas. (Escala exatónica y melismos, ritmos y sonoridades, elementos empleados).

\section{III (HIMNO CHIBCHA)}

Consagrado por las aguas sagradas, el nuevo Zipa ocupa su trono, tres veces ensalzado por el pueblo que canta el himno de la raza. Cortejo. (Melodía compuesta a semejanza del folklore y armonías características. Escala pentatónica) (Posada Amador, 1938).

23. Cinco canciones medioevales, para coro mixto a cuatro voces. Escritas en Medellín, entre el 7 de noviembre de 1938 y el 10 de marzo de 1939, estas piezas corales se pueden considerar como uno de los frutos más logrados de su primera época creativa. El grupo está integrado por Romanza, Canción de mayo, Canción de amor desdeñado, Canción de amor cortés y Canción de amor naciente. Se trata de verdaderas re-creaciones de tres melodías anónimas y dos atribuidas a Moniot de Arras y Jaufré Rudel, todas del siglo XIII. Decimos re-creaciones, que no arreglos, pues más allá de las traducciones, armonizaciones y polifonías de Posada Amador, se encuentra el delicado y seguro creador que es, conocedor como ninguno del tema y el estilo que nos sugiere cada una de estas hermosas páginas. Más que medieval, como los textos, la música de Posada tiene tal vez más aproximación a las formas renacentistas.

Fueron publicadas por el Instituto Interamericano de Musicología en la Editorial Cooperativa Interamericana de Compositores, de Montevideo (Uruguay), en 1943, y por muchos años fueron el único testimonio publicado del autor colombiano. Fueron incluidas, en el disco mencionado, la primera, la tercera y la quinta de la serie.

24. Canción de la vida profunda, para canto (soprano) y piano. Escrita en si bemol, y dedicada a Ignacio Isaza Martínez, esta pieza vocal está basada en el poema homónimo de Porfirio Barba Jacob. Fue compuesta el 23 de mayo de 1939 en Medellín, y su versión definitiva fue concluida en México el 25 de julio de 1978. Como el poema en el cual está basada, escrito en La Habana en 1915, la obra tiene un epígrafe del escritor y filósofo francés Michell Eyquem de Montaigne que dice: "El hombre es cosa vana, variable y ondeante, y es difícil formar sobre él un juicio definitivo y conforme..." (Porfirio Barba Jacob, 1984). 
Sobre esta Canción, y su hermana Nocturno, ambas escritas sobre textos homónimos de Barba Jacob, nos escribió alguna vez el compositor:

Quisiera esperar un tiempo para publicar la Canción de la vida profunda y el Nocturno, porque desearía ver qué acogida tiene la canción de Otto de Greiff... Además me temo que una revista como la de la Universidad de Antioquia, llega más bien a un público académico que a un grupo de profesionistas de la música. Entonces lo que sucedería, si se publicaran ahí esas dos obras, sería que unos cuantos eruditos e intelectuales aficionados a la música (con mucho entusiasmo pero poca preparación musical) se pongan a tratar de tocarlas o cantarlas, con resultados poco halagüeños para ellos mismos y para mí también, pues esas dos obras son difíciles de tocar e interpretar, sobre todo la Canción...: es una obra difícil de tocar y cantar, que solo un buen cantante y un buen pianista pueden dar una ejecución aceptable... Por estas razones le ruego posponer para más adelante su publicación. Otra cosa: la Canción... no está escrita en la tonalidad de mayor o menor, sino en una escala griega... ¡Por eso sería muy plausible que una persona sin preparación creyera, por ejemplo, que puse en la portada un bemol de más! (Y lo mismo ocurre con las Dos canciones criegas: están escritas en modalidades antiguas). Como dice el refrán: Más vale paso que dure que trote que canse (Carlos Posada Amador en carta a Luis Carlos Rodríguez; México, 20 de enero de 1989).

25. Trío, para dos flautas y clarinete, en si bemol mayor. Escrita entre el 24 de abril y el 4 de junio de 1943, y revisada el 16 de septiembre de 1976, es quizás la primera obra compuesta tras su viaje a México. Está integrada por cuatro movimientos: Preludio (andante molto moderato), Deploración (solo de flauta) (moderato ma non troppo), Nocturno (adagio) y Fuga (andantino moderato). La obra tiene dos dedicatorias: el segundo movimiento, a la memoria de su tío Germán Posada Berrío, flautista, y el cuarto, al maestro Guillermo Uribe Holguín, su profesor de fuga. Ha sido incluida en los últimos recitales.

26. Canon, coraly fuga ["sobre el nombre de un amigo"], para piano y cuarteto de cuerdas, en sol bemol mayor.
Concluida el 24 de junio de 1953, y "dedicada al maestro Juan D. Tercero F. ${ }^{7}$ con toda admiración y afecto", es la versión definitiva de la obra homónima para órgano, escrita entre julio y septiembre de 1952. Como su nombre lo sugiere, está dividida en tres movimientos, así: I. Introducción y canon (lento ma non troppo-Moderato scherzoso), II. Coral (molto moderato) y III. Introducción y Fuga (moderato-maestoso).

27. Dúo № 1, para violín y viola. Escrita en 1953, esta breve partitura, junto con las otras dos obras con igual nombre y las Seis variaciones sobre "Estrellita" de M. M. Ponce, fueron concebidas para el disfrute personal del autor -como intérprete de la viola- y de su amigo, el maestro Aurelio Fuentes, reconocido violinista mexicano.

28. Diez romances tradicionales mexicanos, para coro mixto a cuatro voces. Dedicado al eminente folclorista y maestro Vicente T. Mendoza, este trabajo está fechado el 11 de septiembre de 1954. La colección está integrada por los siguientes romances de la tradición hispano-mexicana, armonizados y arreglados por Posada: Rosalinda o las tres hermanas, Román Castillo, Camino de Belén, El Burlador de Sevilla, Una fatal ocasión, El Conde Olinos, Doña Alda, El enamorado y la muerte, Delgadina y Elisa de Mambrú.

Desde el siglo XV, el romance fue, junto con el villancico, la más popular forma de canción en los países de habla hispana. Esta forma literario-musical fue traída al Nuevo Mundo por los primeros exploradores, misioneros y colonizadores, y en la transferencia cultural sobrevivió conservando sus raíces españolas. Así, por ejemplo, los mencionados en esta colección, que se presentan en un lenguaje polifónico tradicional, más cercano al barroco que al renacimiento. Solo Román Castillo fue incluido en el disco mencionado, y se han cantado en homenajes este, El Burlador de Sevilla y El Conde Olinos.

29. Fuga, para órgano, a cinco voces, en re menor. Fechada el 15 de abril de 1958, y dedicada a Jesús Estrada.

7 Juan Diego Tercero Farías 
Sobre ella nos cuenta el propio compositor en forma modesta: "Es una obra sencilla, muy contrapuntística y escrita sobre un tema cromático muy empleado en el barroco. La única originalidad que puede tener es el tratamiento musical" (Carlos Posada Amador en carta a Luis Carlos Rodríguez; México, 20 de enero de 1989).

30. Quinteto de alientos [Sagitario], para flauta, oboe, clarinete, corno y fagote), en si bemol mayor, concluida en 1958. La obra está integrada por los siguientes movimientos: I. Introducción (allegro maestoso) y Fuga (allegro ma non troppo); II. Nocturno (adagio); III. Gallo (allegro non troppo - In tempo di barcarola ma ritmico e preciso - Adagio - Allegretto grazioso), y IV. Marcha humorística (alla marcia, pomposo). La primera página de la obra fue reproducida en facsímil en los artículos ya citados de la revista Compositores de América (Espinosa Grau, 1964) y del libro de Andrés Pardo Tovar (1966).

31. Fuga, para órgano, a cuatro voces, en si bemol mayor. Escrita en 1960, esta sencilla obra, en interpretación histórica de Hernando Montoya Montoya, legendario maestro de capilla de la Catedral Metropolitana de Villanueva, en Medellín, fue incluida en el disco homenaje a Posada Amador ya comentado. Es una obra breve, concebida dentro del espíritu barroco, con un tratamiento organístico propio de la escuela de Buxtehude y Bach.

\section{Seis variaciones sobre "Estrellita" de M. M. Ponce,} para violín y viola, en sol mayor. Dedicada a la memoria del conocido compositor y pedagogo Manuel María Ponce (1882-1948), padre del nacionalismo musical mexicano, y escrita en 1963, como su nombre lo indica, la obra está concebida en la forma de "tema y variaciones". Casi como un muy personal ejercicio camerístico, inspirado en la famosísima canción romántica mexicana, el motivo, presentado en un Adagio ma non troppo, sirve de base a seis variaciones y un interludio, en el siguiente orden: I. Poco più mosso, II. Molto Moderato, III. L'istesso tempo, IV. Deciso, V. Tempo di valse lento, Interludio (Andante) y VI. Moderato assai cuasi marcia. Concebidas de forma que en cada sección se puede reconocer la melodía original, en la obra se exploran timbres y combinaciones y se tejen diversas elaboraciones sonoras para ambos instrumentos de cuerda. Modificaciones rítmicas, melódicas, armónicas y de tempo que, sin embargo, no alteran la exquisita esencia temática de la canción, tan cercana al alma mexicana. Durante la Sexta Semana Cultural de Colombia en México, el 26 de julio de 1997, se presentó en estreno, a cargo de Thalía Eurán, violín, y Mariana Cerda, viola. Como se indicó antes, la obra fue editada impecablemente en 1995, como el primer número de la Colección Compositores Colombianos, por el Centro de Documentación y Edición Musical de Antioquia Notas y Partituras, bajo la dirección del compositor y pedagogo Andrés Posada Saldarriaga.

33. Florilegio lírico coral I, para coro mixto a cuatro voces. Este trabajo hace parte de un largo proyecto en que Posada laboró por unos 25 años y en el cual buscaba presentar a las agrupaciones corales, así como a sus públicos, canciones originales y tradicionales de diversos países y compositores, en arreglos y armonizaciones para cuatro voces mixtas a cappella.

Se conservan del Florilegio lírico coral I dos cuadernos, perfectamente diferenciados. En el primero, fechado en 1967 se integran Doce canciones escocesas y los ya comentados Romances tradicionales mexicanos (Ver № 28). Ya conocidos estos últimos, enumeremos las primeras, todas versiones corales tomadas de la colección de Canciones escocesas op. 108 de Ludwig van Beethoven: Sunset, Oh!, sweet were the hours, The Maid of Isla, Dim, dim is my eye, The sweetest lad, Bonny laddie, highland laddie, The lovely lass of inverness, $O$ thou art the lad of my heart, $O$ how can I be blythe and glad, O Mary at thy window be, Enchantress fare well y Faithfu' Johnie.

34. Camino de Belén, para coro mixto, flauta dulce y cuerdas, en sol mayor. Se trata del romance tradicional mexicano ya mencionado, tomado del Florilegio lírico coral, en arreglo especial del autor, fechado el 12 de agosto de 1968.

35. Canon, para coro a cuatro voces mixtas a cappella, con letra de una copla popular mexicana, sobre el tema 
de la sonata en sol menor para clavecín, conocida como "Fuga del gato" de Domenico Scarlatti, del 17 de diciembre de 1968.

36. Juguete vocal, para coro mixto a cuatro voces, escrito en día no determinado de 1968, sobre la melodía del último movimiento de la famosa sonata en sol menor para violín, conocida como El trino del diablo de Giuseppe Tartini. Con letra popular, en "clave".

37. Fuga, para cuarteto de vientos (flauta, oboe, clarinete y fagot), en si bemol mayor. Obra que también data de 1968.

38. Dúo № 2 ("Tema y Variaciones sobre un nombre"), para violín y viola. Con iguales consideraciones que el numeral 27, la obra data del 25 de febrero de 1972.

39. Fuga a cuatro voces en si bemol mayor. Fechada el 23 de febrero de 1977, en una partitura para piano, no tiene detalles de instrumentación. Además, varias notas con lápiz, que dicen así: "Anteponerle un Preludio" Moderato (Junio 28/1978), en la parte superior y el borde izquierdo "Cuarteto de cuerdas? Oboe, Corno inglés y 2 Fagotes? Oboe (Flauta), Clarinete, Clarinete bajo y Fagot, Fl, Cl, Corno, Fag.

40. Dúo № 3 para violín y viola, en do mayor. Terminado el 26 de julio de 1977, su partitura está dividida en cinco movimientos: I. Preludio (moderato), II. Fuga (molto moderato), III. Canon 1 (tempo di siciliana), IV. Canon 2 (poco allegro) y V. Posludio (allegro). 


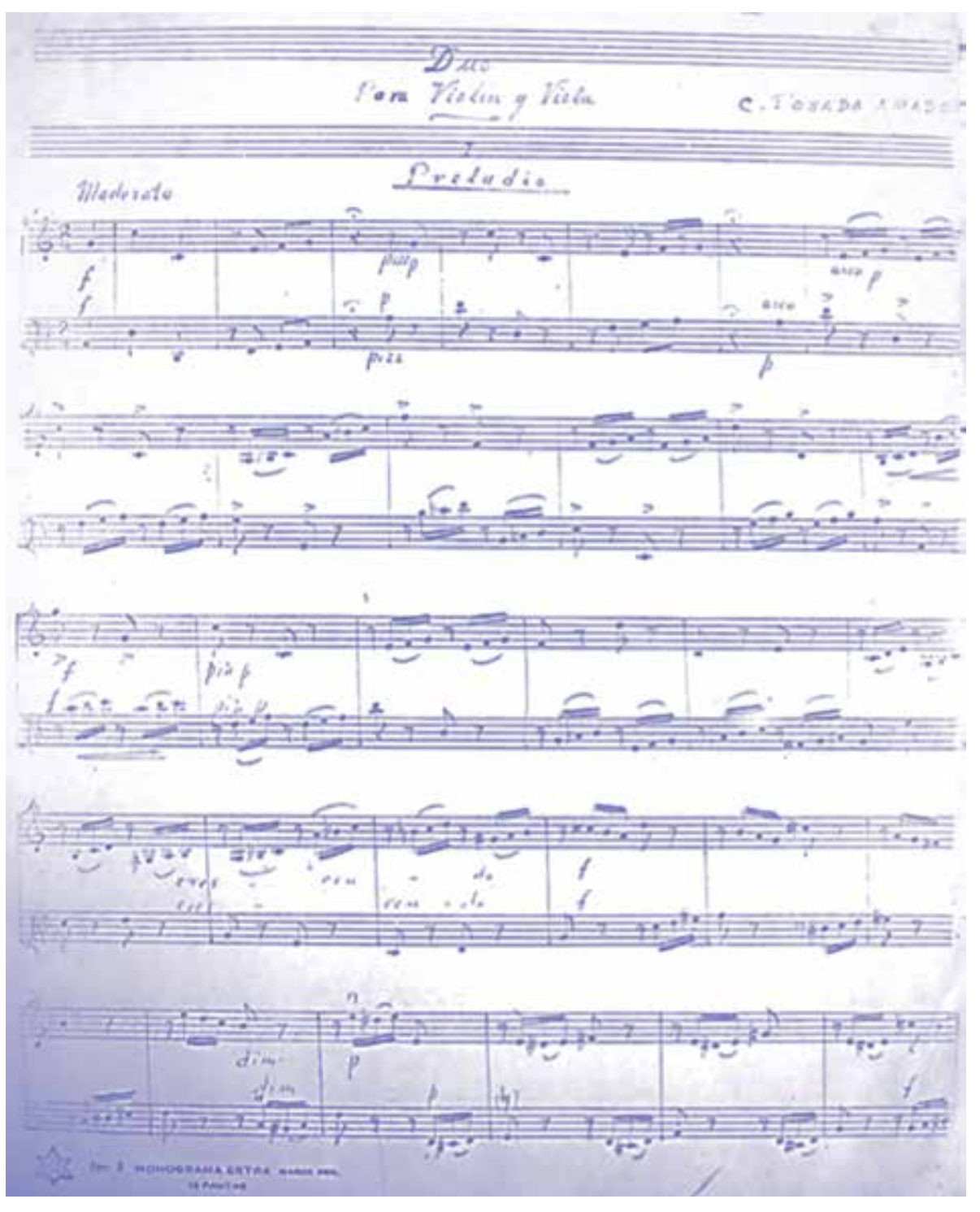

41. Nocturno, para canto (soprano) y piano, en sol bemol mayor, sobre el poema del mismo nombre, original del escritor colombiano Porfirio Barba Jacob. Fue escrito entre el 25 de julio (el mismo día que revisó la Canción de la vida profunda) y septiembre de 1978. Sus características formales son similares a las de la última, su hermana ya comentada en el numeral 22. También fue incluida en el disco mencionado.

\section{Himno Panamericano (o Latinoamericano), para} coro y orquesta, con letra de Rodolfo Brito Moreno, en fa mayor. Compuesto para un concurso, bajo el seudónimo de "Latinern", este trabajo fue terminado el 31 de octubre de 1978.
43. Florilegio lírico coral II, para coro mixto a cuatro voces. Con los mismos comentarios escritos para el numeral 33. Este segundo cuaderno de armonizaciones y arreglos está integrado por Seis canciones rusas (Slava, Dobrinia, Abedul, Estuve en una fiesta, El Sarafán rojo y Bis el sarafán rojo) ${ }^{8}$ y por Dos corales. Data de 1979.

44. Concierto barroco, para clavecín, cuerdas y otros instrumentos (flauta, clarinete, corno, trompeta y

8 Estos son los nombres en español de la canciones: 1. Slava (Слава: gloria), 2. Dobrinia (Добрыня: es el nombre de un guerrero ruso; significa bueno, querido), 3. Abedul (Береза), 4. Estuve en una fiesta (Я был на празднике), 5. Sarafán rojo; es un vestido de mujer (Красный сарафан). Traducciones de la profesora Galina Likosova, del Grupo de Investigación Audiovisual INTERDÍS, de la Universidad Nacional de Colombia, sede Medellín. 
triángulo), en si bemol mayor. Terminado el 10 de marzo de 1981 y dedicado a su hermana Margarita Posada, la obra se divide en tres movimientos: I. Introducción y fuga (adagio - moderato), II. Nocturno: tema y diez variaciones (allegretto) y III. Rondó (allegro). Concebido en la estructura tradicional, incluso con una cadenza en el último movimiento, sobre este trabajo nos escribe el autor:

Es una obra que hay que tocar en el espíritu barroco: nada de fortes a la moderna, mucha claridad en el fraseo, nada de rubatos o "interpretaciones". Basta con tocar bien las notas, sostener el tempo y la música saldrá por sí sola (Carlos Posada Amador en carta a Luis Carlos Rodríguez; México, 20 de enero de 1989).

45. Himno universitario, para coro y orquesta, aunque existe versión para coro y piano, sobre un texto original del compositor, en si bemol mayor. Escrito el 24 de octubre de 1984, también fue presentado en concurso bajo el seudónimo de "Ausus Sum".

46. Preludio, fuga y tocatta, para guitarra. Dedicada a su sobrino, el guitarrista y artista plástico colombiano Carlos Ignacio Vieira Posada, la obra está fechada el 25 de abril de 1989. Como su nombre lo indica, estaba integrada inicialmente por un preludio (moderato assai), una fuga (andante) a cuatro voces, y una tocatta (allegro). Con posterioridad, en septiembre del mismo año, el autor cambió la fuga a cuatro voces original, por una fuga (Molto Moderato) a tres voces, mucho más adecuada para la interpretación guitarrística.

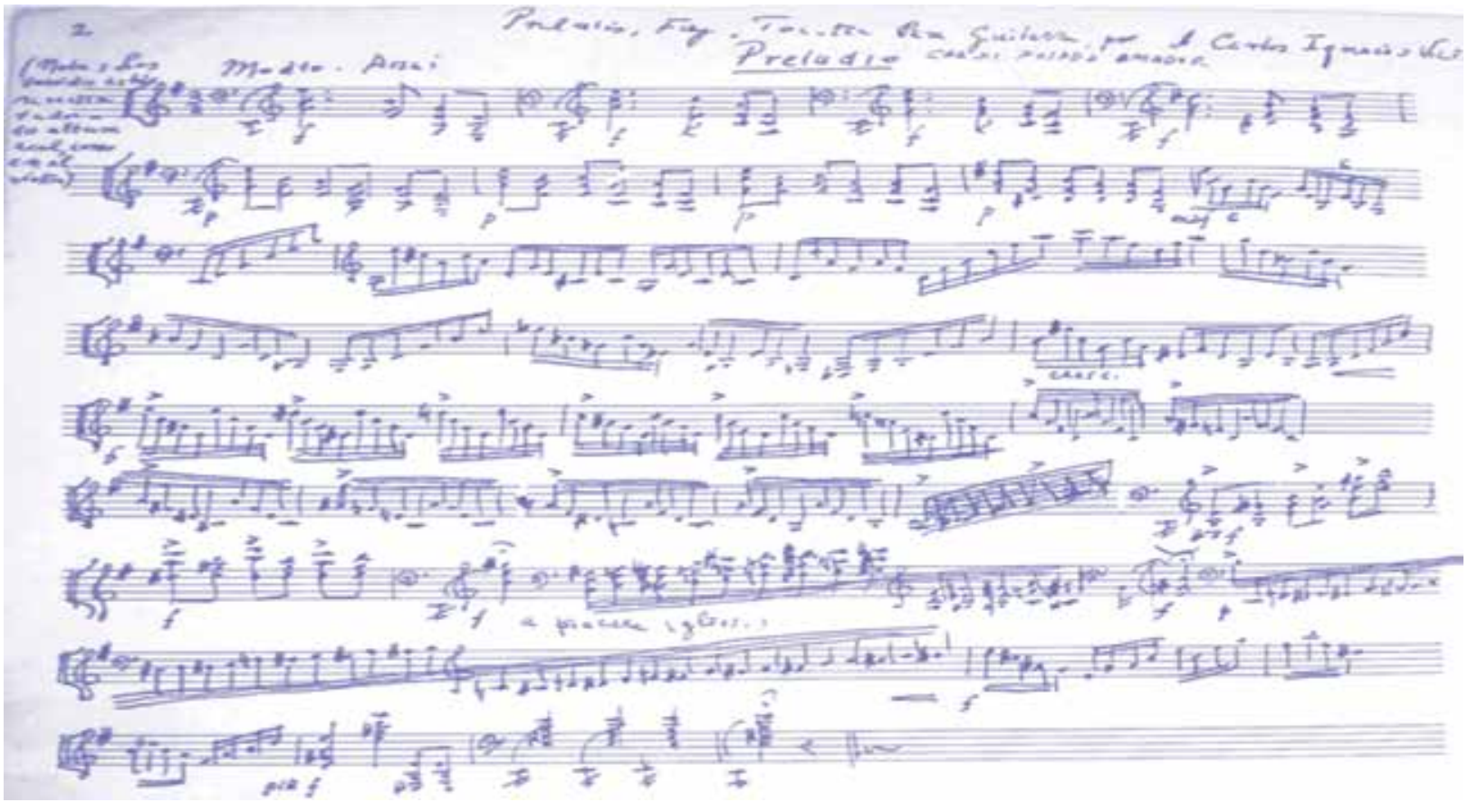

47. La coronación del Zipa (segunda y definitiva versión), ballet en un acto, para orquesta, en mi bemol mayor. Concluida en 1991, con argumento y música originales, esta partitura es quizás la más importante de las realizaciones del maestro Posada Amador. Durante los años 
en los que sostuvimos correspondencia, nos informaba sobre los progresos del trabajo y de lo orgulloso que se sentía de su feliz terminación, fuera de comentar que sería la única versión que él autorizaría para interpretación. Conocida la primera versión, en este catálogo numerada con el numeral 22, veamos el programa de la segunda, que el propio autor nos envió, firmada -ignoramos la razón- bajo el seudónimo (su nombre en italiano) de Carlo di Possa:

Bailarines: Pretendientes a la corona (4), Ancianos Consejeros (3 ó 5), Guardianas de la corona (1 principal y 2 ayudantes), Los desamparados (4 mujeres, 2 hombres), las seductoras (6 u 8 mujeres), Músicos de la tribu (8 ejecutantes en escena), Pueblo (mujeres, hombres y niños, en número suficiente).

Argumento: Es leyenda que los Chibchas, pueblo precolombino del altiplano de Colombia, elegían y coronaban a sus gobernantes, o Zipas, en una ceremonia especial. En un claro del bosque, a orillas de la laguna de Guatavita, ante el altar del dios Bochica, tenía lugar la ceremonia. Cuatro eran las pruebas de aptitud para gobernar que se imponían a los pretendientes a la corona: la de Ingenio, o habilidad para resolver en el acto un problema mecánico; la de Compasión, o ayuda piadosa al desgraciado; la de Dominio de sí mismo, o resistencia al placer amoroso desordenado, y la de Valentía, el peligroso rescate de la corona, arrojada a la laguna. Era elegido y coronado ahí mismo el triunfador en todas las pruebas.

\section{Coreografía:}

1. Amanecer. Evocación por la orquesta del lugar y día de la coronación.

2. Entrada y colocación de los Chibchas al lugar del certamen. Con los Ancianos, las Guardianas de la corona y los Aspirantes a la cabeza, la tribu llega al lugar especial y toma asiento.

3. Invocación a Bochica ante su estatua y altar.

4. Las Guardianas de la corona la develan y ostentan ante todos para su aprecio.

5. Invitación bailada de los Ancianos, con bruscos movimientos, a competir por la corona. 6. Se deja oír la fanfarria de la tribu y se procede a la primera prueba, que consiste en armar un círculo de madera con su diámetro que se entrega en fragmentos. De cuatro pretendientes solo tres pasan la prueba.

7. En la segunda prueba los pretendientes se enfrentan a los Desamparados, que piden ayuda. Solo uno no siente compasión y no les da, como los otros, sus atuendos y joyas. Este queda excluido del certamen.

8. Los dos restantes pretendientes son asediados por las Seductoras, hermosas muchachas, casi desnudas y mimosas, que tratan de llevarlos con ellas al bosque. En diferentes grupos y actitudes los rodean y acarician, hasta lograr que uno de ellos las acompañe.

9. El único pretendiente que queda es saludado por los Ancianos por sus logros.

10. El mayor de los Ancianos recibe de las Guardianas la corona, de oro y con una enorme esmeralda al centro, y la arroja a la laguna, desde la eminencia de las rocas. 
11. El pretendiente se arroja a las aguas en busca de la corona. Después de varios intentos, que el cuerpo de ballet, subido a la eminencia, describe al pueblo con diferentes bailes, logra recuperarla.

12. Con la corona en alto, el pretendiente celebra su victoria con un baile de triunfo.

13. Se oye tres veces la fanfarria de la tribu, en señal de terminación del certamen, y los Ancianos coronan solemnemente al nuevo Zipa.

13 bis. Los ancianos, con ademanes expresivos, proponen un homenaje a Bochica.

14. Todos, con el nuevo Zipa y los Ancianos al frente, honran a su dios con un himno-baile, compuesto en la escala pentatónica, común a las tribus aborígenes. Con este número termina el ballet.

\section{Escenario:}

El escenario representa un claro de bosque. Al fondo, un grupo de rocas obstruye la visión directa de la laguna de Guatavita, cuyas aguas sólo se ven brillar a lo lejos. Una tosca estatua de Bochica, tallada en la roca, se alza unos metros sobre el suelo. En la base se ve un rústico altar. A lo largo hay asientos de piedra para los dignatarios de la tribu. Unas gradas talladas en la roca permiten subir al tope para ver la laguna y presenciar el rescate de la corona. A la izquierda, un sendero desemboca en el claro, por donde llega la tribu. A la derecha, rocas chicas y asientos de piedra para los espectadores. Al centro, un amplio círculo, libre de rocas, sirve para el certamen. Todos los participantes lucen sus mejores galas y joyas para la ocasión (Carlos Posada Amador: documento cuyo original reposa en el archivo del compositor; México, ... de ... de ...).

Una presentación del ballet en concierto, con la versión para piano, fue realizada con el apoyo de una Beca de Creación Artística 2010 de la Alcaldía de Medellín, y con coreografía, dirección artística y reinterpretación argumental de René Ýdrogo, profesor de la Universidad de Antioquia, al frente del ensamble artístico La Otra Compañía.
48. Cuarteto breve ("El hijo pródigo"), para dos violines, viola y cello, en re mayor. Fechada el 20 de marzo de 1992, esta obra está integrada por ocho trozos, tocados en cuatro momentos: I. Ansias de libertad (allegro). II. Placeres-Tema variado (scherzoso). III. Nostalgia del hogar y retorno (lento), IV. Sin indicación, V. Variaciones (tempo di marzia, ma non troppo), y VI. Moderato; se interpretan los cuatro últimos sin solución de continuidad. VII. Allegro y coda. Se puede inferir, por los títulos de la obra toda y de sus movimientos, una indiscutible intención autobiográfica.

Fue estrenado por el Cuarteto 5, en el IX Festival Internacional Música de Cámara Colombiana, programa Mil años de la música, Medellín, el 6 de octubre de 2011.

49. Cinco canciones, para voz (soprano) y piano, sobre poesías de sor Juana Inés de la Cruz (Juana de Asbaje y Ramírez; ¿1648?-1695). Escrito entre el 21 de agosto y el 13 de octubre de 1992, es el último trabajo completo de Posada Amador. Se trata de un verdadero homenaje, no solamente a la primera escritora mejicana, sino al propio país que le acogió, al estilo barroco que cultivó la autora y a la poesía amorosa. El grupo está integrado por cuatro sonetos y una redondilla; las piezas se titulan (por el primer verso del poema), Detente, sombra...; Esta tarde, mi bien...; Dulce deidad...; En perseguirme, mundo..., y Hombres necios que acusáis... Estos textos hacen parte del primer volumen, dedicado a la Lírica personal, de la "Fénix de Méjico" (Sor Juana Inés de la Cruz, 1951).

Dos ellas, las llamadas Esta tarde, mi bien... y Detente, sombra..., se presentaron en estreno absoluto durante la Sexta Semana Cultural de Colombia en México, el 26 de julio de 1997, a cargo de Betty Favila (soprano) y Betty Zanolli (piano).

50. Crespos Caimán, ópera sobre tradiciones antioqueñas, con texto propio, en la que trabajaba todavía al momento de su muerte. El autor nos escribía sobre ella, poco antes de fallecer en diciembre de 1992: 
También he estado tratando de ponerle música a un libreto de ópera, de mi invención, titulado Crespos Caimán, ópera antioqueña, por el lenguaje, las costumbres y el fondo minero que es la base de la historia. Ojalá pueda terminarla el año que viene. Si lo logro, será un jirón de la vida antioqueña en los pueblos pequeños. Ya le daré más detalles, a medida que logre estructurar la ópera. (No será ópera de Arias, Romanzas y otras gracias de la ópera tradicional. El enfoque musical será muy diferente en esto) (Carlos Posada Amador en carta a Luis Carlos Rodríguez; México, 25 de noviembre de 1992).

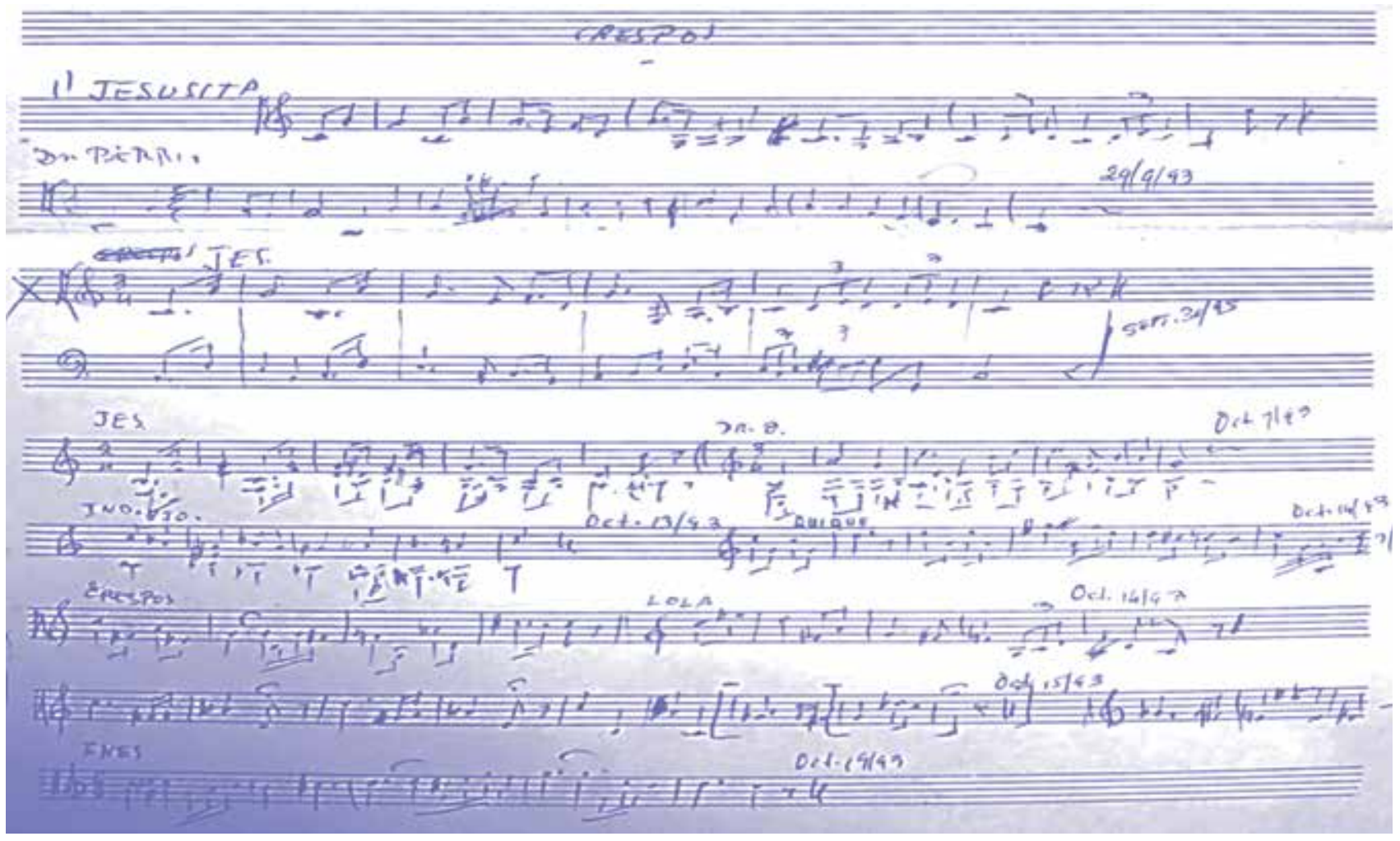

Arreglos, orquestaciones, versiones

Las primeras experiencias de escritura compositiva de Carlos Posada Amador pueden ubicarse en las adaptaciones que hizo para las posibilidades instrumentales de la Orquesta Begué, conjunto activo en la ciudad de Medellín en la época, bajo la dirección del violinista catalán Pedro Begué Monserrat (1883-1956), maestro del compositor.

51. Orquestación del preludio del primer acto de El sueño de Fervaal. Fechado en Medellín, el 7 de mayo de 1925. Es el arreglo de esa sección de la ópera Fervaal [acción musical o drama lírico en tres actos y un prólogo], op. 40 del compositor francés Vincent d’Indy. En la portada de la partitura manuscrita dice: "Es propiedad de la Orquesta Begué".

52. Acompañamiento al segundo movimiento [presto], sobre el bajo continuo, del Concierto para flauta e instrumentos de arco, op. 10 № 13 (RV 428) en re mayor (1728), más conocido como Il Gardellino, de Antonio Vivaldi. Fue dedicado al maestro Gildardo Mojica. 
53. Arreglo para cuerdas del Divertimento K. Anh. 229 \# 1 en si bemol mayor de Wolfgang Amadeus Mozart, originalmente escrito para dos corni di bassetto y fagot. Está dedicado a la memoria de Salvador Nevraumont, fechado en 1958 y con revisión del 22 de junio de 1969. La obra fue interpretada en México por el Grupo instrumental Música Viva.

54. Arreglo para dos flautas dulces del Concierto Pastoral de Johann Melchior Molter, fechado el 14 de diciembre de 1967.

55. Arreglo -parte adicional para viola- del Concierto en fa mayor de Johann Adolph Hasse, fechado el 4 de mayo de 1968.

56. Arreglo para vientos y timbales del anónimo Himno holandés (una melodía conocida desde antes de 1572), también fechado el 4 de mayo de 1968.

\section{REFERENCIAS}

Anglés, H., y Pena, J. (1954). Diccionario de la música Labor, tomo II. Barcelona: Labor.

Anglés, H., y Subirá, J. (1965). Historia de la música, 2ª ed., tomo III (traducción, ampliación y actualización a partir de la 3a edición italiana de la obra homónima de Della Corte, A., y Pannàin, G.). Barcelona: Labor, 1965.

Barreiro Ortiz, C. (1995, 5 de junio). Carlos Posada Amador. Presentación. Ciclo compositores colombianos y norteamericanos del siglo XX. Bogotá: Centro ColomboAmericano, pp. 4-5. Reproducido en el suplemento Dominical de El Colombiano, Medellín, 17 de septiembre de 1995, p. 11.

De Greiff Häusler, O. (1944, 9 de enero). Carlos Posada Amador. En "Crítica musical". Bogotá: El Tiempo.

De Greiff Häusler, O. (1995, 10 de enero). Disco de Posada Amador. En “Comentarios musicales". Bogotá: El Tiempo, p. 3D.

Dufourcq, N. (1969). La música, los hombres, los instrumentos, las obras, tomo 2. Barcelona: Planeta.

Espinosa Grau, G. (1964). Carlos Posada Amador. En Compositores de América, vol. 8. Washington, D. C.: Secretaría General Organización de los Estados Americanos.

Gobernación de Antioquia (1994). Carlos Posada Amador. En La música en Antioquia, volumen 9 (disco de acetato). Medellín: Gobernación de Antioquia.

Instituto Colombiano de Cultura, Colcultura, Centro de Documentación Musical (1992). Compositores colombianos. Vida y Obra. Catálogo N. 1. Bogotá: Gente Nueva.

Matas, J. R. (1966). Diccionario biográfico de la música. 2ª ed. Barcelona: Iberia. 
Mayer-Serra, Ó. (1947). Carlos Posada Amador. En Música y músicos de Latinoamérica. México: 1947.

Pardo Tovar, A. (1966). La cultura musical en Colombia. Historia Extensa de Colombia, vol. XX, tomo 6. Bogotá: Ediciones Lerner/Academia Colombiana de la Historia, 1966.

Porfirio Barba Jacob [M. Á. Osorio] (1984). Poesías. En Joyas de literatura colombiana. Bogotá: Círculo de Lectores.

Posada Amador, C. (1938, 27 de agosto). Notas al programa. Quinto concierto del Festival Iberoamericano de Música de Bogotá. Bogotá: Orquesta Sinfónica Nacional

Posada Saldarriaga, A. (Ed.) (1995). Compositores colombianos, 1. Notas y partituras. Medellín: Centro de Edición Musical de Antioquia. Notas y partituras.

Restrepo Restrepo, J. E. (2010). Investigación y edición crítica de dos piezas para piano del compositor antioqueño Carlos Posada Amador. Artes-La Revista (Medellín: Universidad de Antioquia, Facultad de Artes), 9(16), 88-105.

Riemann, H. (1975). Enciclopedia musical de Hugo Riemann (Riemann Musiklexikon)

Sadie, S. (Ed.) (1980). The New Grove dictionary of music and musicians, vol. 4. Londres: MacMillan.

Scholes, P. A. (1964). Diccionario Oxford de la músi$c a, 9^{\mathfrak{a}}$ ed. Buenos Aires: Sudamericana.

Sor Juana Inés de la Cruz (1951). Méndez Plancarte, A., y Chumacero, A. (Eds.). Obras completas, vol. 1: lírica personal, secciones Sonetos de amor y Discreción y redondillas. México, D. F.: Fondo de Cultura Económica.

Subirá, J. (1953). Historia de la música española e hispanoamericana. Barcelona: Salvat.

Valls Gorina, M. (Ed.) (1967). Enciclopedia Salvat de la Música, tomo IV (revisión y adaptación española de la Encyclopédie de la musique, dirigida por Michel, F.). Barcelona: Salvat.
Zapata Cuéncar, H. (1962). Compositores colombianos. Medellín: Carpel.

Zapata Cuéncar, H. (1973). Compositores antioqueños. Medellín: Granamérica. 